\title{
LITOGEOQUÍMICA E QUÍMICA MINERAL DAS ROCHAS METACARBONATÍTICAS DE ANGICO DOS DIAS, DIVISA BAHIA/PIAUÍ, BRASIL.
}

\author{
LITOGEOCHEMISTRY AND MINERAL CHEMISTRY OF ANGICO DOS DIAS \\ METACARBONATITE ROCKS, DIVISE BAHIA/PIAUÍ, BRAZIL.
}

\author{
Rejane Lima LUCIANO ${ }^{1}$, Antonio Misson GODOY ${ }^{2}$ \\ Universidade Estadual Paulista - UNESP. Email: mgodoy@rc.unesp.br

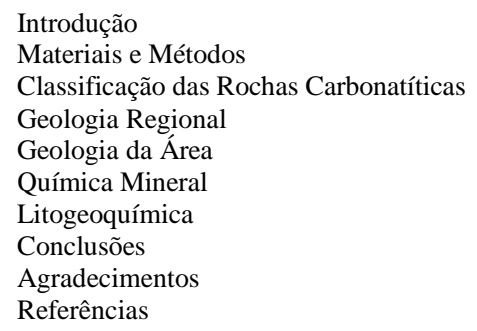

${ }^{1}$ Programa de Pós-Graduação em Geociências, Instituto de Geociências e Ciências Exatas Companhia Baiana de Pesquisa Mineral -CBPM. Email: rejane.lima@cbpm.ba.gov.br

${ }^{2}$ Departamento de Petrologia e Metalogenia, Instituto de Geociências e Ciências Exatas

RESUMO - As rochas do Complexo Metacarbonatítico de Angico dos Dias ocorrem na região do extremo noroeste do estado da Bahia e são constituídas por metacarbonatitos, metassienitos variados, metapiroxenitos, metadioritos, tremolititos, biotitito, metalamprófiros, fenitos e apatititos, que constituem depósito secundário de fosfato residual. Os metacarbonatitos originam um acamamento cumulático, definido por níveis diferenciados em apatita, minerais ferromagnesianos e magnetita, que permitem individualizar cinco tipos petrográficos: apatita metacarbonatito; olivina-apatita metacarbonatito; flogopita-apatita-olivina metacarbonatito; olivina-apatita-biotita/flogopita metacarbonatito e metacarbonatito silicificado. Dados petrográficos e de química mineral apontam a presença de: calcita com exsolução de dolomita; fluorapatita; pseudomorfos de olivina alteradas para serpentina, tremolita, antofilita e magnetita; flogopita; badeleíta; exsolução de ilmenita em magnetita que se altera para hematita; pirrotita; pirita; calcopirita; sulfatos como celestita, barita e baritocelestita e oxi-hidróxidos do tipo goethita e lepidocrocita. O intemperismo dos carbonatitos encontra-se associado com as carapaças ferruginosas e/ou silicificadas, além de concentrar apatita, pode originar alumino-fosfatos do grupo da crandalita, goyazita, gorceixita, plumbogumita, florencita. As associações minerais ígneas anidras e metamórficas de alto grau apresentam-se superimpostas por paragêneses retrometamórficas em fácies xisto verde alto. Dados geoquímicos classificam as rochas metacarbonatíticas principalmente como calciocarbonatitos e aquelas intensamente hidrotermalizadas são classificadas como ferrocarbonatitos e magnesiocarbonatitos.

Palavras-chave: carbonatito; mineralogia, petrografia, geoquímica.

\begin{abstract}
The rocks of Angico dos Dias Metacarbonatite Complex occur in northernmost region of Bahia and consist of metacarbonatites, several metasyenites, metapyroxenites, alkali metadiorites, tremolite rock, biotite rock, metalamprophyres, fenites and apatite rock, which are a secondary deposit of residual phosphate. The metacarbonatites yield a cumulatic layer, defined by different levels in apatite iron-magnesium minerals and magnetite, which allows separating in five petrographic types: apatite metacarbonatite; olivine-apatite metacarbonatite; phlogopite-apatite-olivine metacarbonatite; olivine-apatite-biotite/phlogopite metacarbonatite and silicified metacarbonatite. Petrographic and mineral chemistry data indicate the presence of: calcite with exsolution of dolomite; fluorapatite; olivine pseudomorphs altered to serpentine, tremolite, anthophyllite and magnetite; phlogopite; baddeleyite; exsolution of ilmenite in magnetite that alters to hematite; pyrrhotite; pyrite; chalcopyrite; sulfates as celestite, barite and baritecelestite; and oxy-hydroxides of goethite and lepidocrocite. The weathering of carbonatites is associated with ferruginous and/or silicified shells, and, besides concentrating apatite, can originate alumino-phosphates of the crandalite group, goyazite, gorceixite, plumbogumite, florencite. Anhydrous igneous and metamorphic mineral assemblages of high grade are superimposed by retrometamorphic parageneses in high greenschist facies. Geochemical data classify metacarbonatitic rocks mainly as calcium carbonatites and those intensely hydrothermalized are classified as iron carbonatites and magnesium carbonatites.
\end{abstract}

Keywords: carbonatite; mineralogy; petrography, geochemistry.

\section{INTRODUÇÃO}

No Brasil um dos mais fortes segmentos da economia é o agronegócio, mas a maioria dos seus solos agricultáveis apresentam uma deficiência em relação aos micros e macronutrientes, em função da forte lixiviação, consequência do clima tropical. Os minerais fosfatados naturais são constituídos por mais de um tipo de fosfato e os mais comuns são os fosfatos de cálcio do grupo da apatita.
No território brasileiro utiliza-se para fertilizantes a apatita, matéria-prima proveniente das raras ocorrências de rochas carbonatíticas, sendo que $95 \%$ da sua capacidade de produção de concentrados apatíticos resulta de minérios associados a complexos alcalino-carbonatíticos, que são encontrados em dois ambientes geológicos distintos: (i) Magmáticos-Complexos alcalino- 
carbonatíticos mesozoicos em que os minérios de mais elevados teores se formaram por enriquecimento supergênico de carbonatitos apatíticos e piroxenitos apatíticos, a exemplo de Araxá- MG, Catalão I e II- GO, Jacupiranga (atualmente exaurido e explorado o minério primário), Tapira e Juquiá- SP, que estão em fase de exploração e respondem pela maior parte da produção (Comin-Chiaramonti \& Gomes, 2005), além de Anitápolis-SC, IperóSP, Patrocínio-MG, Ouvidor-GO e; (ii) Ortomagmáticos-Complexos alcalino-carbonatíticos proterozoicos metamorfizados, nos quais ocorreram também concentrações residuais. Os complexos alcalino-carbonatíticos ortomagmáticos são limitados aos de Morro de Seis LagosAM, Mutum-AM e Maicuru-PA, inseridos na parte norte do Cráton Amazônico e Angico dos Dias-BA, localizado no extremo noroeste do Cráton São Francisco.

O Brasil é o quinto produtor mundial de fertilizantes fosfatados, mas a produção não acompanhou o grande desenvolvimento da agropecuária e o país tornou-se o terceiro maior importador mundial de fertilizantes e o segundo no caso específico dos fosfatados. A importância de suprir as necessidades de fertilizantes fosfatados sempre foram metas governamentais e a necessidade de novas descobertas de rochas fosfatadas é de importância nas pesquisas geológicas.

A mineralização de rochas carbonatíticas de Angico dos Dias já foi lavrada de modo rudimentar desde a década de 1970 e foram consideradas antieconômicas a partir das pesquisas geológicas da época. Os trabalhos geológicos no corpo carbonatítico se intensificaram em 1984 pela Companhia Brasileira de Metalurgia e Mineração-CBMM, a partir de novas descobertas de fosfato, mas um grande desafio era estabelecer um empreendimento industrial para a tecnologia de exploração da época, em uma região carente de infraestrutura e de recurso hídrico do semiárido da Bahia.

As atividades de mineração das rochas do Complexo Metacarbonatítico de Angico dos Dias (CMCAD) tiveram início somente em 2005, superando o grande desafio do empreendimento, a falta de infraestrutura hídrica local. Por meio de tecnologia de concentração a seco, permitiram-se situações específicas do aproveitamento dos minérios fosfáticos, significando um aumento nas reservas, na vida útil das jazidas e na exploração mais racional do bem mineral pela Empresa Galvani - Unidade de Mineração de Angico dos Dias.

Neste contexto, o corpo metacarbonatítico de Angico dos Dias apresenta importância no cenário de fosfato regional e a produção de concentrados apatíticos resulta de minérios que se encontram associados a uma composição mineralógica muito variável, dentro da própria jazida.

A necessidade constante na atualização de dados geológicos, petrográficos e geoquímicos permite a adequação atual da composição e da variação química das rochas do complexo (Luciano, 2016).

\section{MATERIAIS E MÉTODOS}

As amostras coletadas durante os trabalhos de campo foram encaminhadas para os laboratórios especificados abaixo.

As Análises Petrográficas foram realizadas na Companhia Baiana de Pesquisa Mineral (CBPM), utilizando-se um microscópio binocular de luz polarizada modelo Axio Scope. A1-ZEISS do Brasil.

As Análises Geoquímicas foram realizadas pela SGS-Geosol Laboratórios Ltda por intermédio da CBPM, onde foram analisados elementos maiores, menores, traços e terras raras. Nesse contexto, foram analisados $\mathrm{Al}_{2} \mathrm{O}_{3}, \mathrm{Ba}$, $\mathrm{CaO}, \mathrm{Cr}_{2} \mathrm{O}_{3}, \mathrm{Fe}_{2} \mathrm{O}_{3}, \mathrm{~K}_{2} \mathrm{O}, \mathrm{MgO}, \mathrm{MnO}, \mathrm{Na}_{2} \mathrm{O}$, $\mathrm{P}_{2} \mathrm{O} 5, \mathrm{SiO}_{2}, \mathrm{Sr}, \mathrm{TiO}_{2}, \mathrm{~V}$, Zn e Zr pelo método analítico de preparação de pastilhas fundidas com acabamento em espectrometria de massas com fonte de plasma indutivamente acoplados (ICPMS); Ag, Ce, Co, Cs, Cu, Dy, Er, Eu, Ga, Gd, Hf, Ho, La, Lu, Mo, Nb, Nd, Ni, Pr, Rb, Sm, Sn, Ta, Tb, Th, Tl, Tm, U, W, Y e Yb pelo método analítico de espectrometria de emissão atômica com fonte de plasma indutivamente acoplado (ICP-AES) e; Au, Pd e Pt pelo método analítico Fire Assay por absorção atômica.

As Análises de Microscópico Eletrônico de Varredura (MEV) foram realizadas em lâminas delgadas polidas e recobertas com carbono em Microscópio JEOL-JSM-6010LA, acoplado ao detector de EDS (Energy Dispersive X-Ray Spectrometer), que realiza análises químicas qualitativas e semi-quantitativas dos seus 
constituintes mineralógicos.

As Análises de Química Mineral por Microssonda Eletrônica foram realizadas nas mesmas lâminas delgadas polidas e metalizadas com carbono, utilizadas no MEV, para a obtenção de dados quantitativos de química mineral (olivina, serpentina, ilmenita e biotita) em equipamento JEOL-JXA-8230, acoplado a detector de WDS (Wavelength Dispersive X-Ray Spectrometers).

As análises do MEV e da Microssonda foram executadas nos laboratórios de Microssonda Eletrônica e de Microscopia Eletrônica de Varredura do Departamento de Petrologia e Metalogenia (DPM/IGCE/UNESP) - Campus de Rio Claro.

\section{CLASSIFICAÇÃO DAS ROCHAS CARBONATÍTICAS}

A nomenclatura e classificação mais utilizada é a proposta pela IUGS (International Union Geological Sciences), publicada por Streckeisen (1979) que define "carbonatito como rocha ígnea com sílica $<10 \%$ e que contém mais de $50 \%$ de minerais magmáticos carbonatíticos primários”. Estas recomendações foram adotadas também por Woolley \& Kempe (1989) e Le Maitre (2002).

A nomenclatura proposta pela IUGS é a recomendada, mas existem alguns termos da literatura antiga que ainda podem ser utilizados, a exemplo de: sovito para carbonatito calcítico de granulação grossa e alvikito de granulação fina, rauhaugito para carbonatito dolomítico de granulação grossa e beforsito de granulação fina, carbonatito siderítico ou anquerítico e carbonatito alcalino.

Streckeisen (1979) propõe designações das rochas em relação à porcentagem de Ca e Mg, sendo denominado de calcita carbonatito (90$\left.100 \% \mathrm{CaCO}_{3}\right)$, calcita-dolomita carbonatito (50-90\% $\mathrm{CaCO}_{3}$ ), dolomita-calcita carbonatito $\left(50-90 \% \mathrm{MgCO}_{3}\right)$ e dolomita carbonatito (90$100 \% \mathrm{MgCO}_{3}$ ).

No caso da não identificação dos tipos de carbonatos, a exemplo de rochas afaníticas, os carbonatitos deverão ser classificados com base em análise química de rocha total pelo diagrama CMF, atendendo a porcentagem em peso de $\mathrm{CaO}, \mathrm{MgO}$ e $\left(\mathrm{FeO}+\mathrm{Fe}_{2} \mathrm{O}_{3}+\mathrm{MnO}\right)$. Na utilização da proposta de Le Maitre (2002), deve-se respeitar duas situações para classificação das rochas: com teores de $\mathrm{SiO}_{2}>$ $20 \%$ são silicocarbonatito e com teor de $\mathrm{SiO}_{2}<$ $20 \%$ podem ser os calciocarbonatitos $\mathrm{CaCO}_{3}>$ $80 \%$, magnesiocarbonatitos $\mathrm{MgCO}_{3}>\mathrm{FeO}+$ $\mathrm{Fe}_{2} \mathrm{O}_{3}+\mathrm{MnO}$, ferrocarbonatitos $\mathrm{MgCO}_{3}<\mathrm{FeO}+$ $\mathrm{Fe}_{2} \mathrm{O}_{3}+\mathrm{MnO}$ (Woolley, 1982) e natrocarbonatitos ricos em (Na). Segundo Gittins (1989) o magma carbonatítico pode ser classificado de duas formas: primários e associados.
Os carbonatitos primários são corpos menos frequentes, isolados, individualizados e sem relação com outros tipos de rochas alcalinas e podem originar-se diretamente por fusão de uma fonte mantélica.

Os carbonatitos associados que são mais frequentes, ocorrem em associação com os complexos silicáticos ultrabásicos-alcalinos, geralmente apresentam múltiplos estágios de intrusão e envolvem processos petrogenéticos como cristalização fracionada e/ou imiscibilidade de líquidos.

Barker (1989) define estas ocorrências como magmas que intrudem a crosta terrestre a partir de um mecanismo do tipo hot spot definido por plumas mantélicas responsáveis pela geração de magma, que se encontram associadas aos falhamentos extensionais profundos existentes na crosta que funcionariam como condutos e permitiriam o emplacement dessas rochas.

Woolley \& Kjarsgaard (2008) propõem a divisão dos carbonatitos em oito classes, conforme o tipo de rocha alcalina associada. As rochas da Série Carbonatíticas de Angico dos Dias encontram-se relacionadas à associação carbonatítica-alcalina do grupo 5 , os carbonatitos associados a traquito (ou sienito) caracterizando uma associação de rochas alcalinas supersaturadas a saturadas em $\mathrm{SiO}_{2}$.

Gittins (1989) propõe a gênese dos magmas carbonatíticos, essencialmente a partir dos três processos, mas o que não impede que atuem conjuntamente: (a) a partir de um melt com origem no manto parcialmente carbonatado e metassomatizado que produzirá magmas carbonatíticos primários e magmas silicatados separados, (b) fracionamento a baixa pressão na crosta de um magma parental derivado do manto (normalmente nefelinito carbonatado) e (c) separação imiscível em níveis crustais rasos do magma silicatado subsaturado depois de diferenciação prolongada. 
Os processos propostos de Gittins (1989) encontram-se similares às propostas de Hall (1996) para a geração do magma carbonatítico: (a) como produto inicial de fusão parcial de um manto portador de uma pequena proporção de carbonatos (carbonatitos primários),

(b) como produto final de diferenciação de um líquido silicático contendo carbonato dissolvido,

(c) por imiscibilidade de líquidos em um sistema carbonatítico-silicático.

\section{GEOLOGIA REGIONAL}

As rochas do Complexo Metacarbonatítico de Angico dos Dias localizam-se no distrito de Angico dos Dias, a noroeste do Estado da Bahia e a sul do Estado do Piauí, no município de Campo Alegre de Lourdes-BA. Quanto aos aspectos geológicos, estão inseridas no extremo norte do segmento geológico do Bloco Gavião, intrusivas em uma associação de rochas gnáissicas e migmatíticas arqueana-paleoproterozoica do Complexo Gnáissico-Migmatítico Sobradinho-Remanso. Localizam-se no contexto do limite norte do Cráton São Francisco (Almeida, 1977), com as faixas de dobramentos marginais Rio Preto e Riacho do Pontal (Alkmim et al., 1993) e refletem um arcabouço tectônico superimposto neoproterozoico (Luciano, 2016) (Figura 1A). As ocorrências das rochas carbonatíticas são controladas principalmente por um trend de lineamentos tectônicos de direção NE-SW (Silva et al., 1988 e Alkmin et al., 1993).

Os trabalhos geológicos do corpo carbonatítico intensificaram com a CBMM, quando se iniciou um programa de prospecção preliminar, que resultou nos principais trabalhos da área, produzidos por Silva et al. (1987, 1988), Mariano (1987), Torquato (1987) e Liberal \& Cassola (1989). Posteriormente, a literatura geológica específica das rochas metacarbonatíticas deve-se a Silva et al. (1997), Lapin et al. (1999), Gomes et al. (2001), Antonini et al. (2003) e Luciano (2016).

Estudos específicos enfocando a natureza da apatita nas frentes de lavra e do aproveitamento e beneficiamento econômico do minério de fosfato devem-se a Kahn et al. (1990) e Santos (2001).

Silva et al. (1987, 1988) classificam as rochas como metacarbonatitos e/ou metasovito, tendo na constituição mineralógica principal apatita, olivina serpentinizada, flogopita, magnetita e calcita. As rochas associadas ao complexo carbonático são constituídas por sienitos e subordinadamente ocorrem piroxenitos, álcali dioritos e lamprófiros, comu- mente gnaissificados e/ou milonitizados. Os sienitos ocorrem lateralmente aos carbonatitos e não foram observadas evidências de processos de fenitização nas litologias do complexo e de suas encaixantes. Silva et al. (1988) apresentam dados químicos dessas rochas e evidenciam o conteúdo elevado de apatita. Os elevados conteúdos de ETR e dos valores das razões de ETRL/ETRP indicam que os litotipos poderiam originar-se da fusão parcial de granada peridotito do manto superior, o que gerou magma basáltico alcalino e este por cristalzação fracionada constituiria os diversos litotipos.

No trabalho de Silva et al. (1988) são apresentadas as datações U-Pb em zircão e badeleíta, dados sobre traços de fissão em grãos de apatita e análise isotópica para carbono e oxigênio. Segundo Mariano (1987), o método U-Pb mostra uma concórdia de $2.010 \pm 6 \mathrm{Ma}$, considerada como a idade de cristalização do carbonatito. Os dados de traços de fissão em apatita forneceram a idade de 336 $\pm 16 \mathrm{Ma}$, atribuída ao último evento termal na área, com temperatura $<100^{\circ} \mathrm{C}$ e sugere-se que esta idade corresponda ao estabelecimento da Bacia do Parnaíba. A análise isotópica de carbono e oxigênio, que determina os isótopos estáveis de $\delta^{13} \mathrm{C} / \delta{ }^{18} \mathrm{O}$, em amostras de calcita de carbonatitos, apresentam os valores médios de $\delta^{13} \mathrm{C}=-6,73 \pm 0,46 \%$ e $\delta^{18} 0=12,26 \pm 0,91 \%$ (Torquato, 1987).

Segundo Liberal \& Cassola (1989), amostras de carbonatito apresentam valores elevados de $\mathrm{P}_{2} \mathrm{O}_{5}$ (7 a 14\%), $\mathrm{CaO}(35,2$ a 48,4\%), $\mathrm{BaO}$ $(0,04$ a $0,49 \%)$ e $\mathrm{SrO}(0,87$ a $1,18 \%)$ e em relação aos elementos menores os teores são baixos de Nb, Ta, Th e V. O minério, definido como apatitito, é mais rico em $\mathrm{P}_{2} \mathrm{O}_{5}$ e resultante de processos de enriquecimento supergênico, devido a maior estabilidade da apatita em relação aos carbonatos e silicatos perante os processos intempéricos.

Lapin et al. (1999) destacam a morfologia linear dos corpos de carbonatitos a sua associação com cinturões móveis e a falha- 
mentos profundos, razão que define estas rochas metacarbonatíticas como a única do gênero até então conhecida no Brasil.

Lateralmente, ao corpo carbonático, os metassienitos apresentam um zoneamento, que sugere não se tratar de uma sequência de rochas magmáticas intrusivas alcalinas, mas sim, de fenitos reomórficos e metassomáticos, produ-zidos pela ação do magma carbonatítico sobre antigos gnaisses. Gomes et al. (2001), identificam para estas rochas teores: altos de $\mathrm{Ba}, \mathrm{Pb}, \mathrm{Sr}, \mathrm{Y}$, baixos de Rb, U, Ta e $\mathrm{Nb}$ e enriquecimento ETRL.

Antonini et al. (2003) apresentam para as rochas carbonatíticas uma mineralogia e características texturais magmáticas parcialmente preservadas, devido ao fraco reequilíbrio metamórfico, imposto pelo metamorfismo em fácies xisto verde. O conteúdo de elementos terras raras dos carbonatitos são muito altos, apresentam valores médios de (3.979 \pm 718ppm), mostram altos valores de ETRL/ETRP e La/Yb (215 \pm 23$)$, como a maioria dos carbonatitos magmáticos précambrianos. Os carbonatitos também são enriquecidos em ${ }^{18} \mathrm{O}\left(\delta^{18} \mathrm{O}=11,9\right.$ a $\left.15,8 \%\right)$, possivelmente devido a processos secundários (a ex. metamorfismo e alteração), enquanto os isótopos de carbono estão na faixa de "carbonatitos primários" ( $\left.\delta^{13} \mathrm{C}=-5.7 \mathrm{a}-7,1 \%\right)$. A relação dos valores iniciais ${ }^{87} \mathrm{Sr} /{ }^{86} \mathrm{Sr}$ e ${ }^{143} \mathrm{Nd} /{ }^{144} \mathrm{Nd}$ dos carbonatitos mostram que estes não foram sensivelmente modificados por processos de alteração. Seus valores de $\varepsilon^{t} \operatorname{Sr}(20,0$ a 25,0$)$ e $\varepsilon^{t} \mathrm{Nd}(0,7 \mathrm{a}-4,5)$, indicam fontes mantélicas enriquecidas (Antonini et al., 2003).

Segundo Luciano (2016) a evolução das rochas metacarbonatíticas encontra-se inicialmente associada às plumas mantélicas e domeamento crustal por mecanismos distensivos, com consequentemente rifteamento da crosta arqueana-paleoproterozoica de composição tonalítica-granodiorítica-trondhjemítica do Complexo Sobradinho-Remanso.

O emplacement dos carbonatitos ocorre em zonas de cisalhamento profundos. Posteriormente estas rochas são submetidas à tectônica colisional compressional paleoproterozoica em fácies anfibolito alto.

As formas lenticulares finais destes corpos e a superposição de associações minerais de paragênese retrometamórfica em fácies xisto verde foram interpretadas como produto da tectônica compressiva colisional (tangencial e transcorrente) neoproterozoica.

\section{GEOLOGIA DA ÁREA}

As rochas do Complexo Metacarbonatítico de Angico dos Dias representam uma associação carbonatítica de idade paleoproterozoica identificada no âmbito do Cráton São Francisco, intrudido em rochas do embasamento gnáissico-migmatítico e que aflora no sopé de uma escarpa constituída por arenitos e conglomerados do Grupo Serra Grande da Bacia do Parnaíba. Dispõe-se em dois conjuntos de corpos com os direitos minerários pertencentes à Mineração Galvani e a Companhia Baiana de Pesquisa Mineral (CBPM). O corpo secundário, mais restrito, encontra-se localizado ao norte da lavra, nas proximidades da Fazenda Pimenteira, e o corpo principal está localizado na mina de fosfato da Mineração Galvani (Figura 1B). As rochas são compostas predominantemente por metacarbonatitos e metassienitos e, secundariamente, podem ocorrer metapiroxenitos, metadioritos, tremolititos e metalamprófiros que exibem deformações miloníticas superpostas. As rochas metacarbonatíticas são constituídas por calcita e apatita, além de dolomita, olivina serpentinizada, flogopita, biotita e magnetita.

Os minerais ígneos anidros e metamórficos de alto grau apresentam-se superimpostos por paragêneses retrometamórficas em fácies xisto verde alto. Esta mineralogia está exemplificada na figura 2.

\section{QUÍMICA MINERAL}

A partir da caracterização petrográfica, foram realizadas as análises químicas qualitativas e semi-quantitativas com o Microscópico Eletrônico de Varredura (MEV) em todos os constituintes minerais presentes nas lâminas delgadas polidas, enquanto as análises a partir de Microssonda foram aplicadas aos grupos minerais: às olivinas serpentinizadas, às biotitas/flogopitas e aos óxidos. 

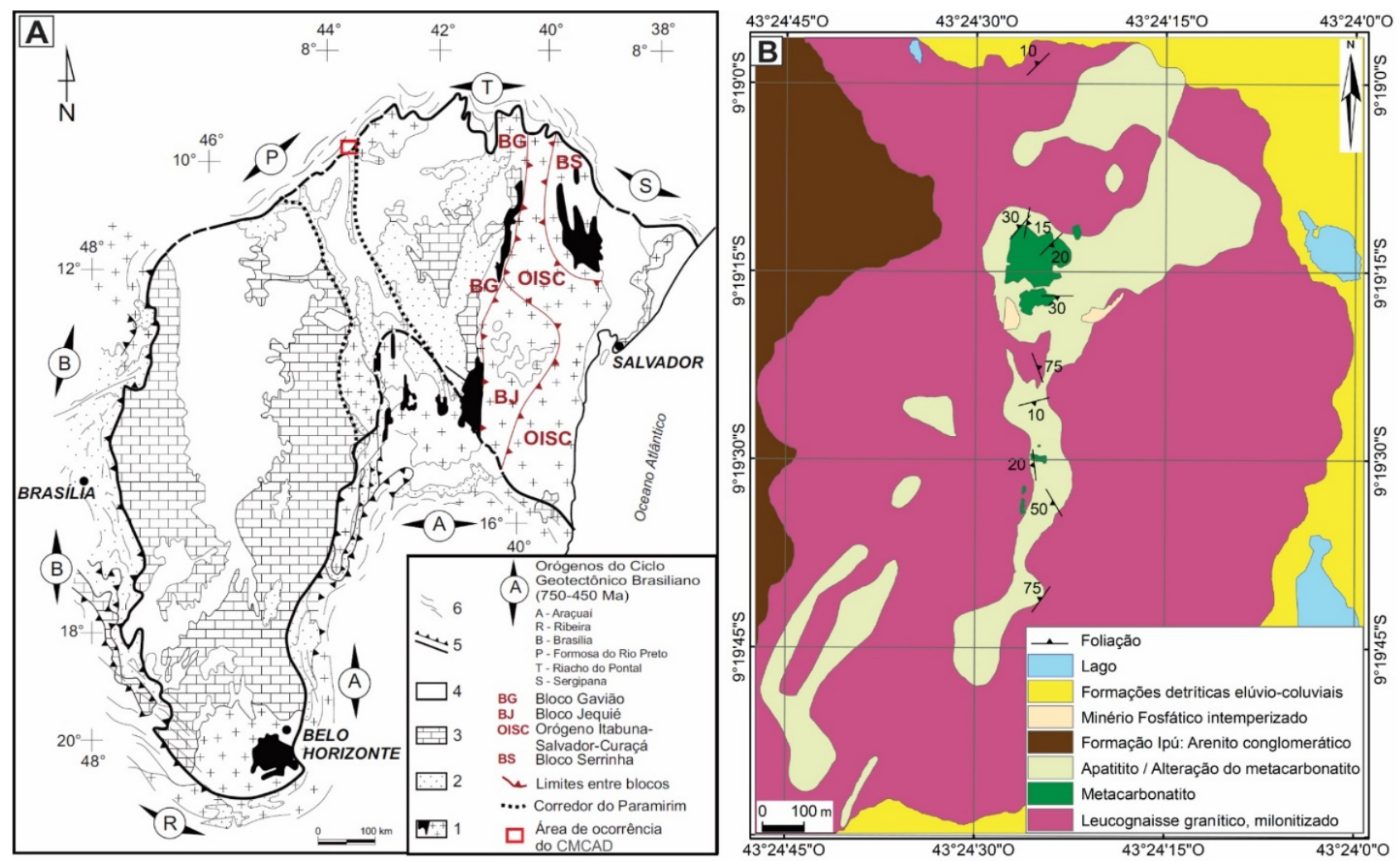

Figura 1. (A) Mapa esquemático dos limites e as maiores unidades estruturais do Cráton São Francisco (Mod. de Alkmim et al. (1993). (B) Mapa Geológico com as localizações das rochas metacarbonatíticas (mod. de Galvani, 2013). Legenda: (A) 1) Embasamento Arqueano/Paleoproterozoico com sequências Greenstone Belts (em preto); 2) Coberturas Paleo e Mesoproterozoicas do Supergrupo Espinhaço; 3) Coberturas Neoproterozoicas do Supergrupo São Francisco; 4) Coberturas Fanerozoicas; 5) Limites do Cráton (ALMEIDA, 1977; CRUZ e ALKMIM, 2006); 6) Lineamentos correspondentes aos cinturões de dobramentos Brasilianos.

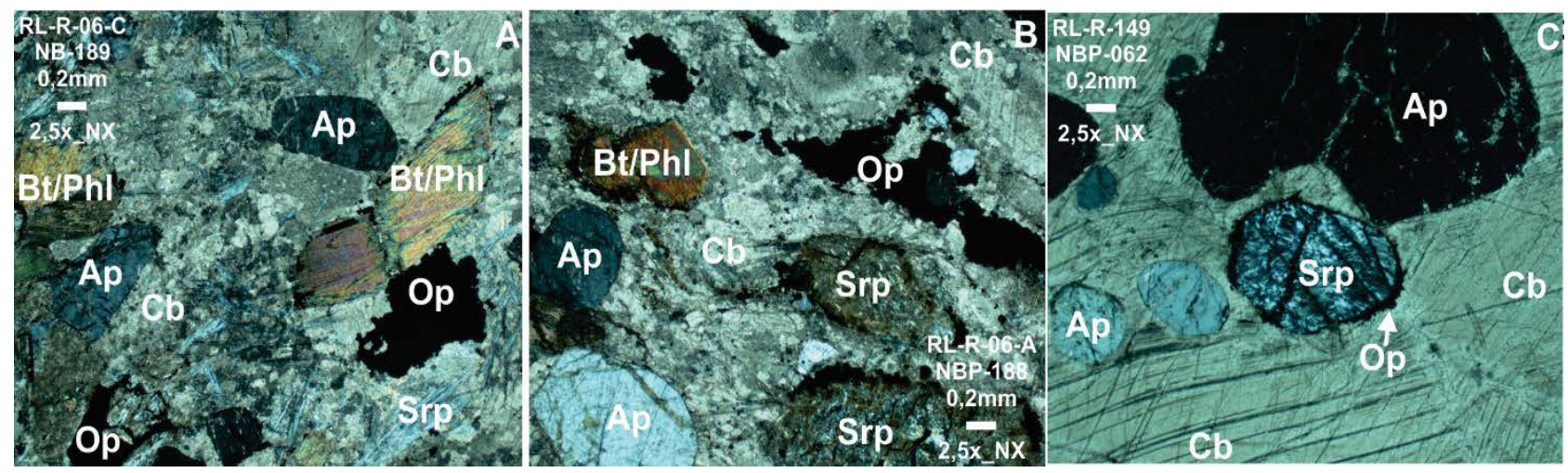

Figura 2. A, B, C) Fotomicrografias dos principais minerais dos metacarbonatitos. (A) Apatita-Flogopita-Olivina Metacarbonatito com matriz composta por carbonato (Cb), biotita (Bt) e/ou flogopita (Phl), minerais opacos (Op) e fenocristais de apatita (Ap) e serpentina-olivina (Srp); (B) Olivina-Apatita Metacarbonatito com fenocristais de apatita (Ap), minerais opacos (Op) e pseudomorfos de olivina serpentinizada (Serp), imersos numa matriz composta por carbonato (Cb), biotita (Bt) e/ou flogopita (Phl); (C) Apatita-Flogopita-Olivina Metacarbonatítico com fenocristais de apatita (Ap), carbonato (Cb) e pseudomorfos de olivina serpentinizada (Serp). Polarizadores cruzados (NX).

A apatita é especialmente abundante, sendo a fluorapatita $\left[\mathrm{Ca}_{5}\left(\mathrm{PO}_{4}\right)_{3} \mathrm{~F}\right]$ o mineral de minério dos metacarbonatitos.

Resultados analíticos de fluorapatitas obtidos pelo MEV indicam não haver variações composicionais significativas entre os cristais analisados ou nas várias porções de um mesmo cristal, além de confirmar os elevados teores de flúor (Figura 3). Revela-se a presença de cristais de monazita [(Ce, La, Th) $\left.\mathrm{PO}_{4}\right]$ como diminutos cristais nas bordas da fluorapatita e preenchendo algumas fraturas nesse mineral.

Verifica-se que este mineral é pobre em tório e rico em cério e lantânio e que parte do conteúdo de elementos terras raras é substituído pelo cálcio.

Além dos grupos e gerações acima, também podem ocorrer fosfatos secundários aluminosos 

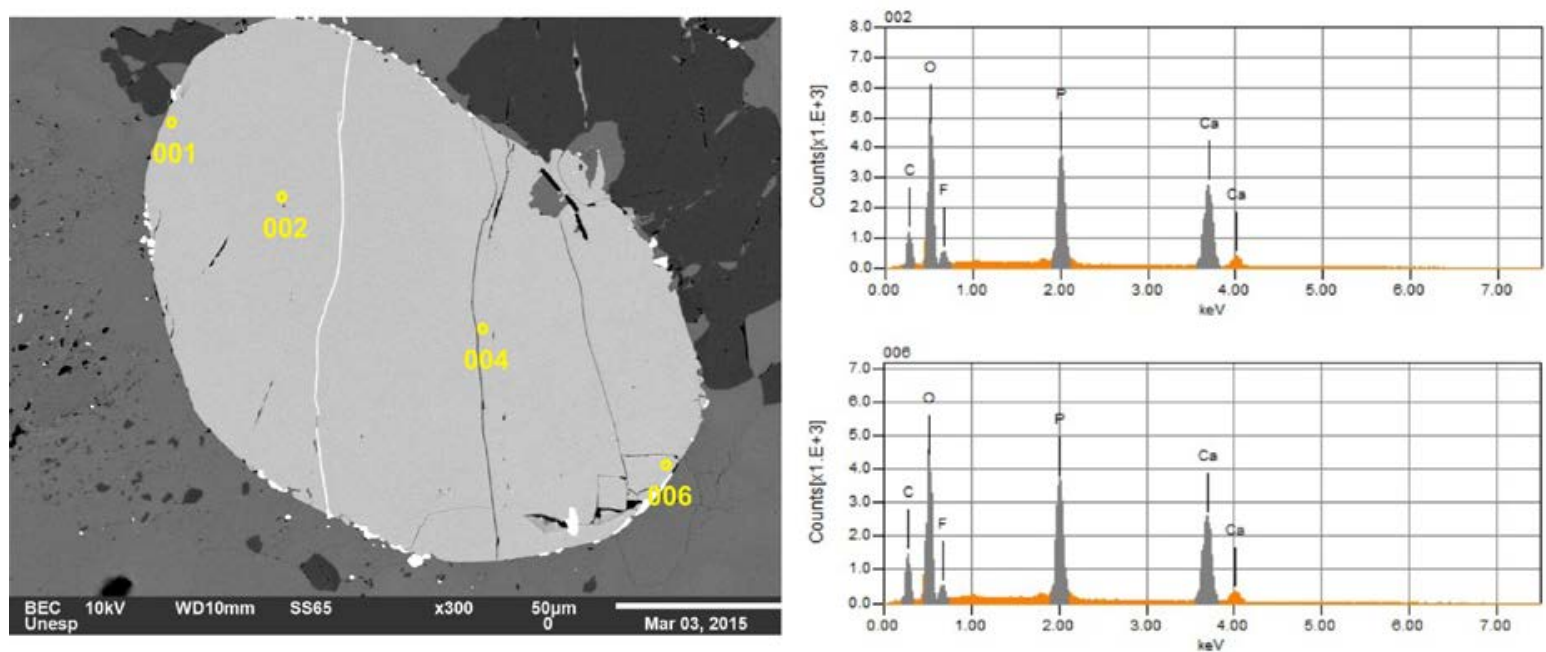

Figura 3. Imagem de microscópio eletrônico de varredura (elétrons retroespalhados) de cristal de fluorapatita.

da família da crandalita [(Ba, Sr, Ca) $\mathrm{Al}_{3}$ $\left.\left(\mathrm{PO}_{4}\right)_{2} \quad(\mathrm{OH})_{5} \cdot \mathrm{H}_{2} \mathrm{O}\right]$, que representam a evolução da fosfatogênese com o intemperismo; os mais comumente observados são a gorceixita e a goyazita; crandalita também pôde ser observada, embora com menor frequência. Acredita-se que o bário para a formação da gorceixita seja proveniente da alteração de feldspato potássico presente frequentemente nas rochas encaixantes. A olivina (forsterita) $\left[\mathrm{Mg}_{2} \mathrm{SiO}_{4}\right]$ apresenta composição de $\mathrm{Fo}_{82,1-92,0}$ (Figuras 4, $5 \mathrm{~A}$ e $5 \mathrm{~B}$ ), o que reflete o conteúdo de ferro (5,65\% e 10,9\%), e encontram-se serpentinizadas em condições metamórficas em fácies xisto verde alto, o que resulta na formação de: serpentina (crisólita) $\left.{ }_{2} \mathrm{Mg}_{3}\left(\mathrm{Si}_{2} \mathrm{O}_{5}\right)(\mathrm{OH})_{4}\right]$, antofilita $\left[\left(\mathrm{Mg}, \mathrm{Fe}^{+2}\right)_{7} \mathrm{Si}_{8} \mathrm{O}_{22}(\mathrm{OH}, \mathrm{F})_{2}\right]$, magnetita $\left[\left(\mathrm{Fe}^{+2} \mathrm{Fe}^{+3}\right)_{2} \mathrm{O}_{4}\right]$ e tremolita $\left[\mathrm{Ca}_{2} \mathrm{Mg}_{5} \mathrm{Si}_{8} \mathrm{O}_{22}(\mathrm{OH})_{2}\right]$.
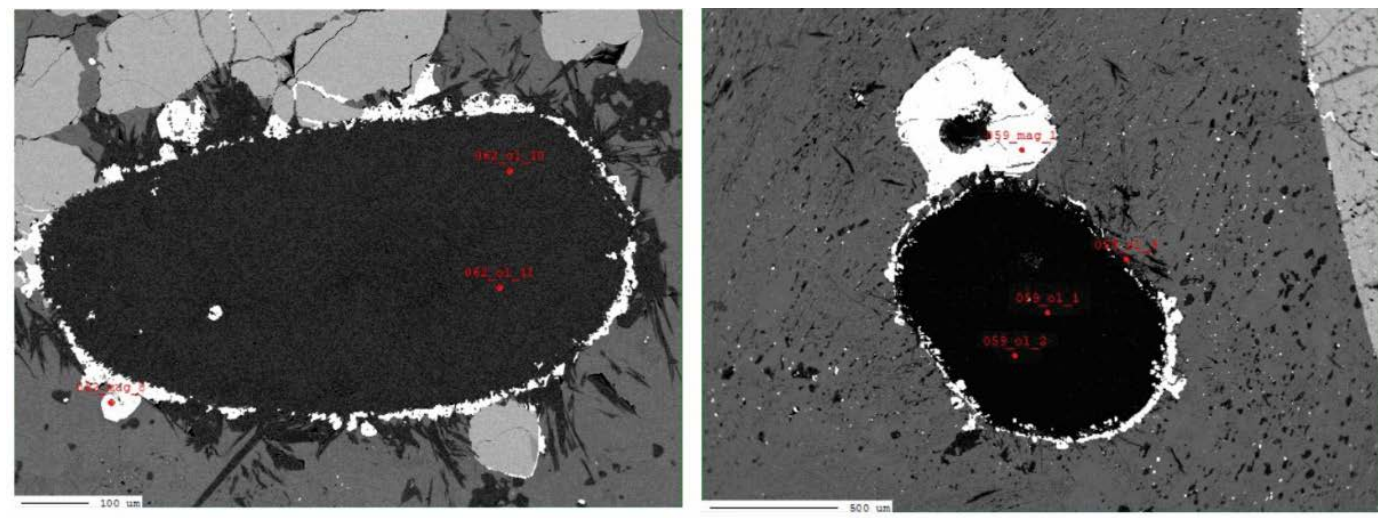

\begin{tabular}{|c|c|c|c|c|c|}
\hline Amostra & RL-149 & RL-149 & Amostra & RL-149 & RL-149 \\
\hline Unidade & 062 ol 10 & 062_ol_11 & Unidade & 062_ol_10 & 062_ol_11 \\
\hline $\mathrm{SiO}_{2}$ & 41,929 & 41,133 & Si & 1,247 & 1,250 \\
\hline $\mathrm{TiO}_{2}$ & 0,000 & 0,000 & $\mathbf{T i}$ & 0,000 & 0,000 \\
\hline $\mathrm{Al}_{2} \mathrm{O}_{3}$ & 0,437 & 1,008 & Al & 0,015 & 0,036 \\
\hline $\mathrm{Cr}_{2} \mathrm{O}_{3}$ & 0,000 & 0,000 & $\mathrm{Cr}$ & 0,000 & 0,000 \\
\hline $\mathrm{Fe}_{2} \mathrm{O}_{3}$ & 0,000 & 0,000 & $\mathrm{Fe}^{3}$ & 0,000 & 0,000 \\
\hline $\mathrm{FeO}$ & 10,010 & 9,740 & $\mathrm{Fe}^{2}$ & 0,249 & 0,248 \\
\hline $\mathrm{MnO}$ & 0,041 & 0,075 & Mn & 0,001 & 0,002 \\
\hline $\mathrm{MgO}$ & 33,522 & 32,237 & Mg & 1,487 & 1,461 \\
\hline $\mathrm{CaO}$ & 0,017 & 0,104 & $\mathrm{Ca}$ & 0,001 & 0,003 \\
\hline TOTAL & 85,956 & 84,297 & Total Cátions & 3,000 & 3,000 \\
\hline $\mathrm{Te}$ & 0,059 & 0,113 & & & \\
\hline Fo & 85,574 & 85,242 & & & \\
\hline $\mathbf{F a}$ & 14,335 & 14,448 & & & \\
\hline Ca-OI & 0,031 & 0,198 & & & \\
\hline TOTAL & 100,00 & 100,00 & & & \\
\hline
\end{tabular}

Figura 4. Análise química e composicional de olivinas em microssonda eletrônica (elétrons retroespalhados). 


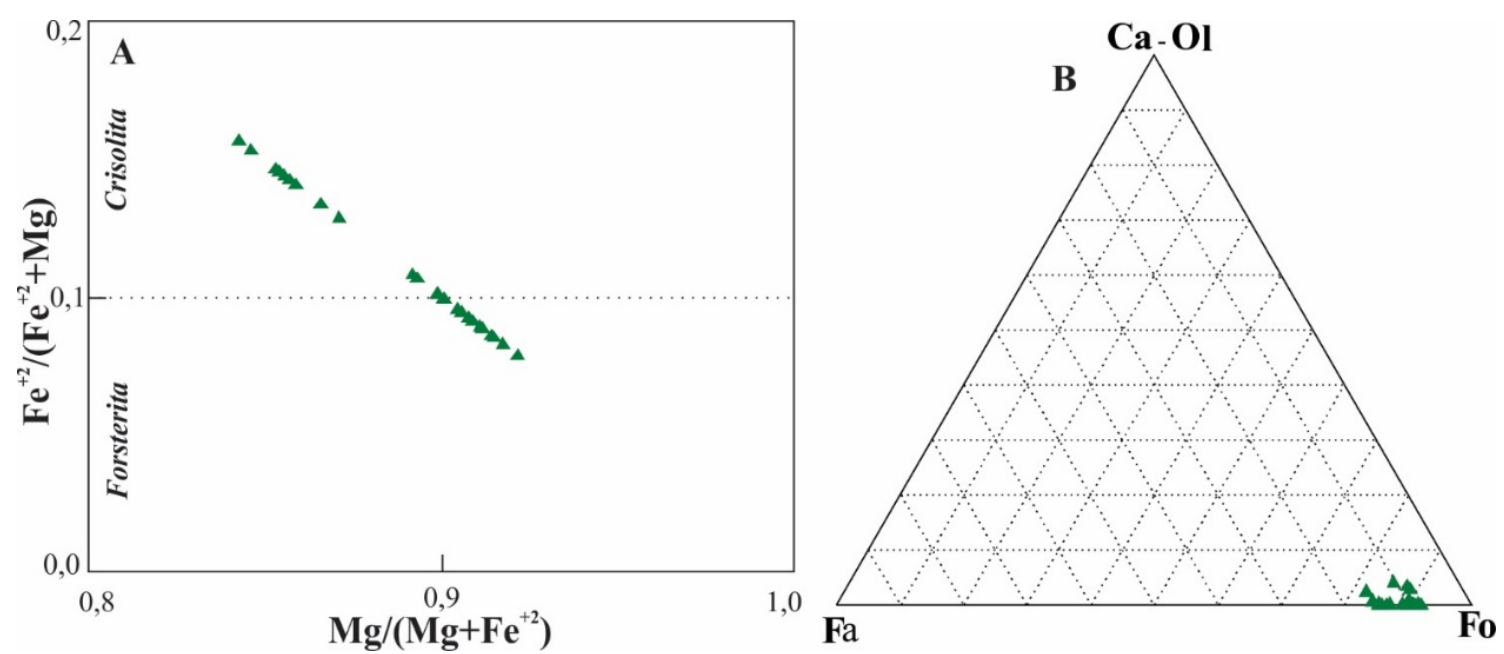

Figura 5. A) Diagrama de classificação para a variação composicional de olivinas. B) Diagramas da composição forsterita com algum percentual de ferro de olivinas.
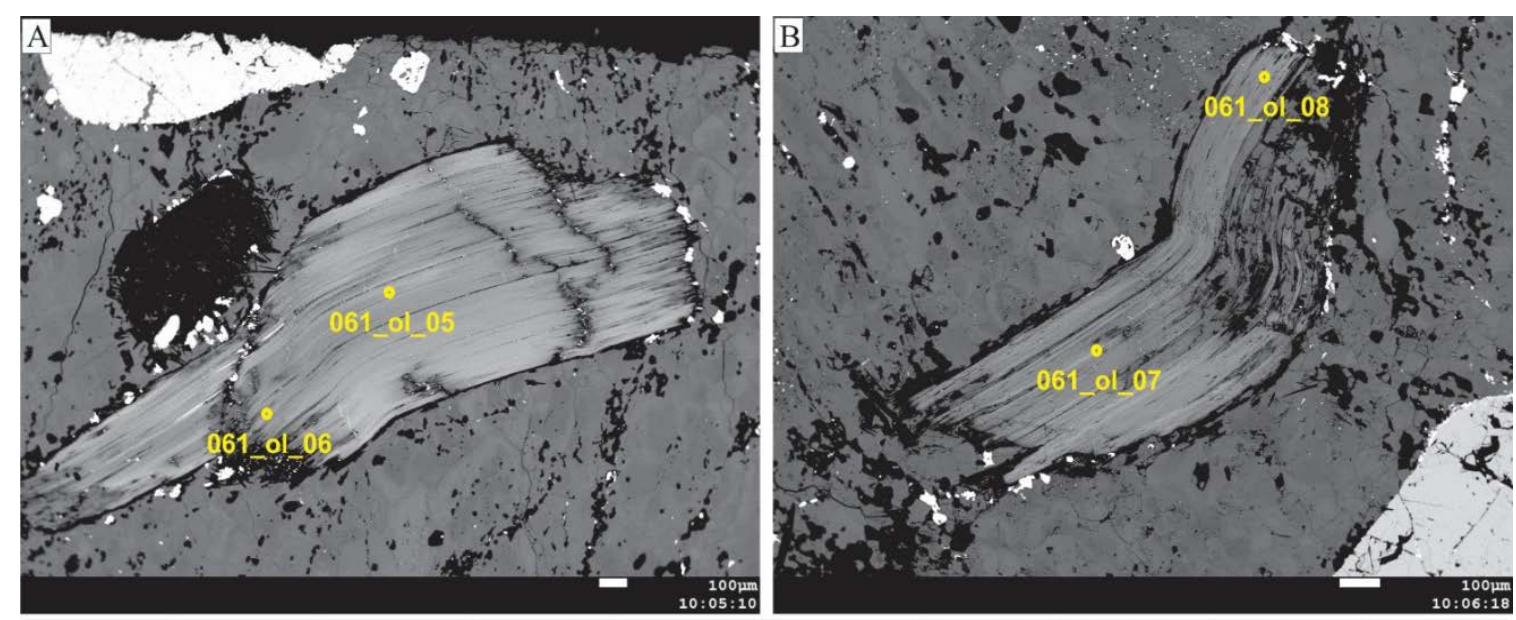

\begin{tabular}{|c|c|c|c|c|c|c|c|c|c|}
\hline Amostra & RL-061 & RL-061 & RL-061 & RL-061 & Amostra & RL-061 & RL-061 & RL-061 & RL-061 \\
\hline Unidade & 061_bt_05 & 061_bt_06 & 061_bt_07 & 061_bt_08 & Unidade & 061_bt_05 & 061_bt_06 & 061_bt_07 & 061_bt_08 \\
\hline $\mathrm{SiO}_{2}$ & 36,746 & 36,031 & 35,913 & 33,584 & $\mathbf{S i}$ & 5,509 & $5, \overline{427}$ & $5, \overline{449}$ & 5,370 \\
\hline $\mathrm{TiO}_{2}$ & 1,937 & 1,832 & 2,005 & 1,969 & Ti & 0,218 & 0,208 & 0,229 & 0,237 \\
\hline $\mathrm{Al}_{2} \mathrm{O}_{3}$ & 14,107 & 14,190 & 14,136 & 13,634 & $\mathrm{Al}^{+4}$ & 2,491 & 2,519 & 2,528 & 2,570 \\
\hline $\mathrm{FeO}$ & 6,410 & 5,724 & 5,669 & 5,345 & $\mathrm{Al}^{+6}$ & 0,003 & 0,000 & 0,000 & 0,000 \\
\hline MnO & 0,020 & 0,053 & 0,044 & 0,052 & $\mathrm{Fe}$ & 0,804 & 0,721 & 0,719 & 0,715 \\
\hline MgO & 22,068 & 23,331 & 22,380 & 21,615 & Mn & 0,003 & 0,007 & 0,006 & 0,007 \\
\hline $\mathrm{CaO}$ & 0,000 & 0,000 & 0,000 & 0,000 & Mg & 4,932 & 5,239 & 5,062 & 5,152 \\
\hline $\mathrm{Na}_{2} \mathrm{O}$ & 0,544 & 0,279 & 0,477 & 0,306 & $\mathrm{Ca}$ & 0,000 & 0,000 & 0,000 & 0,000 \\
\hline $\mathrm{K}_{2} \mathrm{O}$ & 7,060 & 6,542 & 6,597 & 5,993 & $\mathrm{Na}$ & 0,158 & 0,081 & 0,140 & 0,095 \\
\hline $\mathrm{BaO}$ & 5,306 & 5,343 & 5,986 & 6,381 & $\mathbf{K}$ & 1,350 & 1,257 & 1,277 & 1,222 \\
\hline $\mathbf{F}$ & 0,627 & 0,636 & 0,704 & 0,685 & $\mathbf{B a}$ & 0,312 & 0,315 & 0,356 & 0,400 \\
\hline $\mathrm{Li}_{2} \mathrm{O}^{*}$ & 0,000 & 0,000 & 0,000 & 0,000 & $\mathbf{L i}^{*}$ & 0,000 & 0,000 & 0,000 & 0,000 \\
\hline $\mathrm{H}_{2} \mathrm{O}^{*}$ & 3,702 & 3,679 & 3,618 & 3,425 & Subtotal & 15,780 & 15,775 & 15,766 & 15,767 \\
\hline Subtotal & 98,527 & 97,640 & 97,529 & 92,989 & $\mathbf{F}$ & 0,297 & 0,303 & 0,338 & 0,346 \\
\hline $\mathrm{O}=\mathrm{F}, \mathrm{Cl}$ & 0,264 & 0,268 & 0,296 & 0,288 & OH* $^{*}$ & 3,703 & 3,697 & 3,662 & 3,654 \\
\hline TOTAL & 98,263 & 97,373 & 97,233 & 92,701 & TOTAL & 19,780 & 19,775 & 19,766 & 19,767 \\
\hline Y Total & 5,950 & 6,174 & 6,016 & 6,111 & & & & & \\
\hline X Total & 1,820 & 1,654 & 1,773 & 1,717 & & & & & \\
\hline Al Total & 2,493 & 2,519 & 2,528 & 2,570 & & & & & \\
\hline
\end{tabular}

Figura 6 - A) Análise química quantitativa de flogopitas em microssonda eletrônica (elétrons retroespalhados).

A mica apresenta composição compatível à da flogopita primária $\left[\mathrm{K}_{2} \mathrm{Mg}_{6}\left(\mathrm{Si}_{2} \mathrm{Al}_{2} \mathrm{O}_{4}\right)(\mathrm{OH})_{4}\right]$ e encontra-se deformada e com a composição modificada por um ou mais eventos tectonotermais. Apresenta teores de ferro entre (5,34\% e $10,28 \%)$, titânio entre $(1,69 \%$ e 3,12\%) e bário entre (1,26\% e 8,16\%) (Figura 6A). As análises químicas das flogopitas no diagrama de classificação da origem de minerais do grupo da biotita (Figuras 6B, 7A e 7B) são condizentes com o campo de biotitas primárias reequilibradas. 

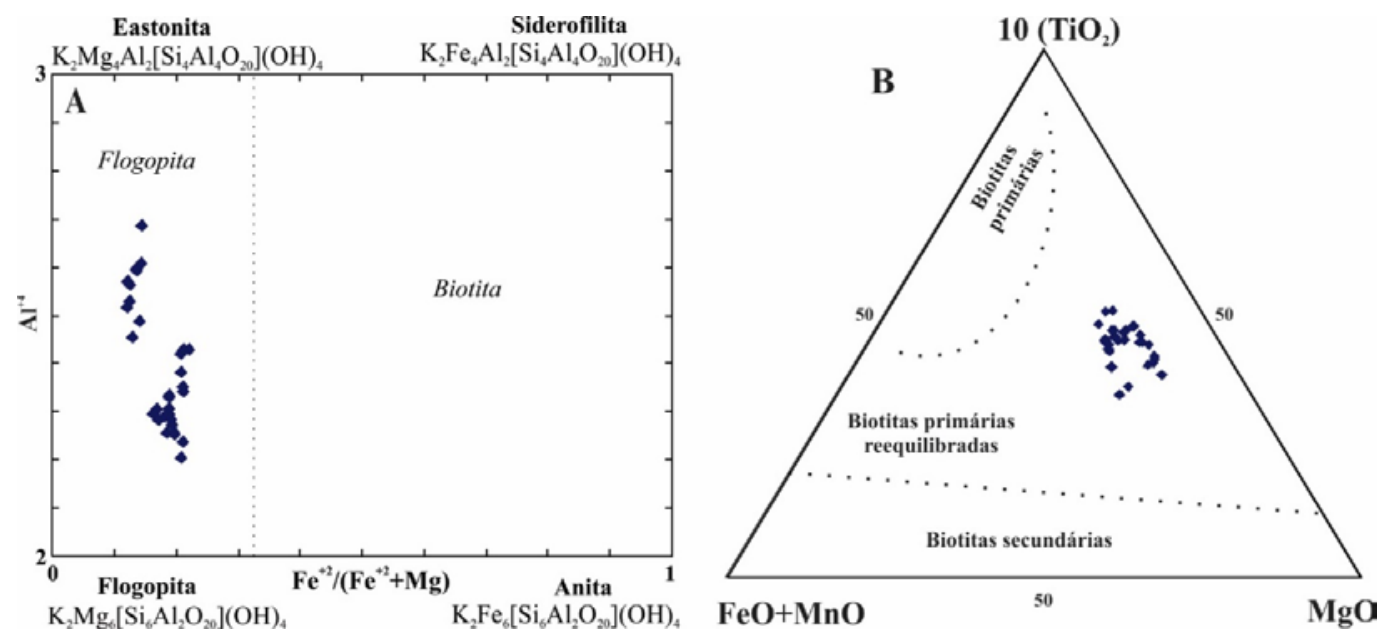

Figura 7 - A) Diagrama composicional de flogopitas. B) Diagrama de classificação da origem de minerais do grupo da biotita para amostras de flogopita.

A dolomita $\left[\mathrm{CaMg}\left(\mathrm{CO}_{3}\right)_{2}\right]$ encontra-se exsolvida em cristais de calcita (Figura 8A), enquanto a principal fase mineral dos carbonatitos, a calcita $\left[\mathrm{CaCO}_{3}\right]$, pode apresentar algum percentual de magnésio e estrôncio em substituição ao cálcio, associado a cristais de antofilita nas bordas dos pseudomorfos de olivina.

A variação composicional dos subtipos carbonatíticos identificados possibilita a presença marcante de calcita nas fácies calciocarbonatito e, consequentemente, um aumento de dolomita se faz presente nas fácies magnesiocarbonatito. Nas fácies ferrocarbo- natito espera-se pela presença de conteúdos ferrosos (anqueríticos) na proximidade dos locais enriquecidos em magnetita.

Os cristais de antofilitas aciculares encontram-se desenvolvidas a partir das bordas dos pseudomorfos de olivina e se adentram na massa carbonatítica, situação em que a calcita apresenta algum percentual de magnésio e estrôncio em substituição ao cálcio (Figura 8B). Os episódios tardios de carbonatos constituem preenchimentos intersticiais de fraturas ou formação de redes anastomosadas de venulações associadas aos produtos de transformação dos carbonatos.
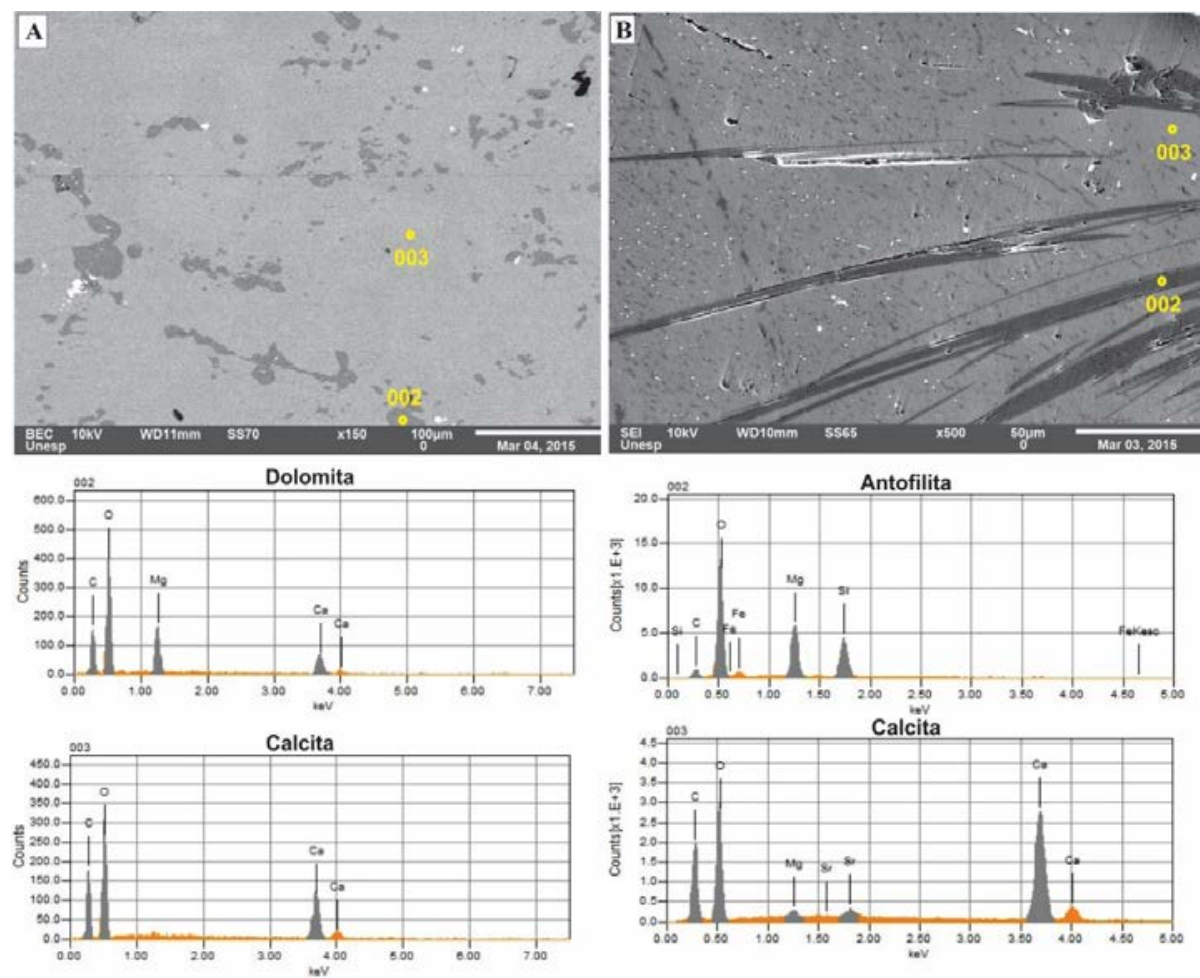

Figura 8. A) Imagem de microscópio eletrônico de varredura (elétrons retroespalhados): calcita com exsoluções de dolomita. B) Imagem de microscópio eletrônico de varredura de detalhe do cristal de antofilita crescido entre grãos de calcita e calcita com variação na composição. 
Os principais óxidos são a magnetita $\left[\left(\mathrm{Fe}^{+2} \mathrm{Fe}^{+3}\right) \mathrm{O} 4\right]$ com a presença de exsolução de ilmenita [Fe $\left.{ }^{+2} \mathrm{TiO}\right]$ (Figuras 9, 10), submetidos a

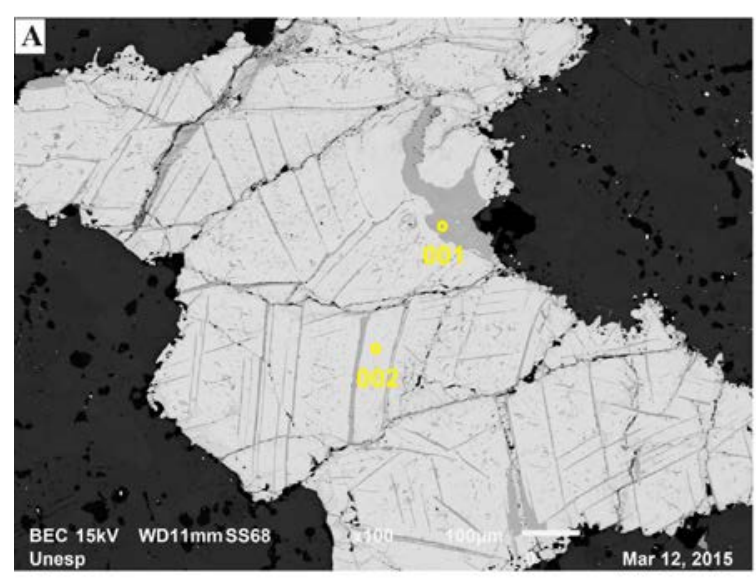

processos de oxidação de ferro, por metassomatismo/hidrotermalismo associado ao metamorfismo regional em fáceis xisto verde alto.

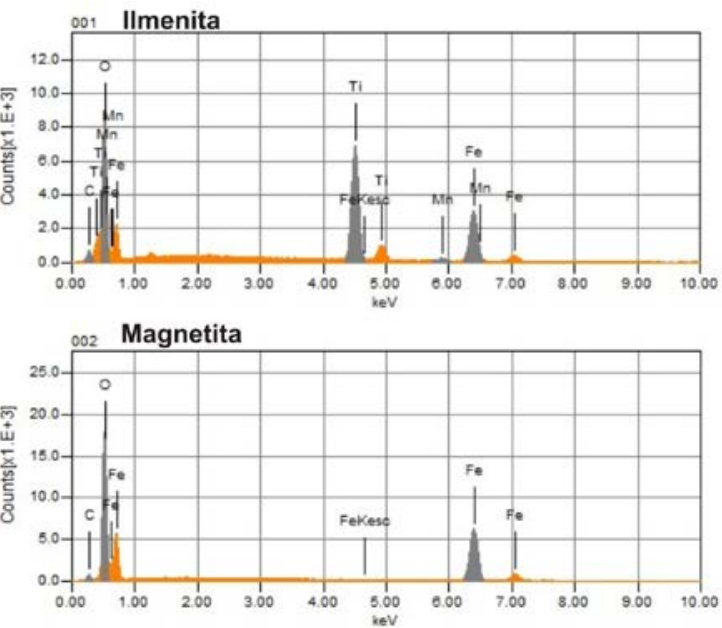

Figura 9 - Imagem de microscópio eletrônico de varredura (elétrons retroespalhados) de cristal de magnetita com exsolução de ilmenita.

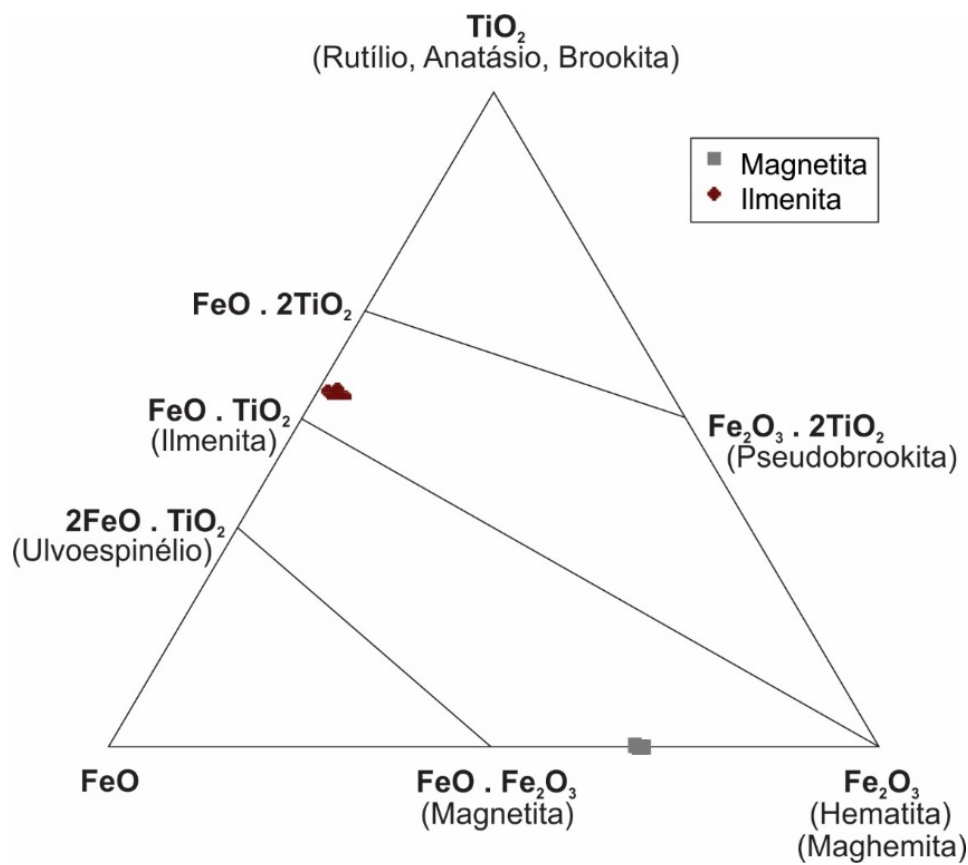

Figura 10. Diagrama de classificação para minerais do grupo do espinélio para amostras com magnetita e ilmenita do metacarbonatito

Os minerais opacos (na maioria sulfetos) são constituídos por cristais de pirrotita $\left[\mathrm{Fe}_{(1-}\right.$ $\left.{ }_{x)} \mathrm{S}\right]$, pirita $\left[\mathrm{FeS}_{2}\right]$, calcopirita $\left[\mathrm{CuFeS}_{2}\right]$ e badeleíta $\left[\mathrm{ZrO}_{2}\right]$ que ocorrem como inclusão no carbonato e nas bordas e centro das olivinas (Figura 11A e 11B).

Os sulfatos são constituídos principalmente por cristais de celestita $\left[\mathrm{SrSO}_{4}\right]$ e baritocelestita [(Ba, $\left.\mathrm{Sr}) \mathrm{SO}_{4}\right]$, que ocorrem imersos na matriz ou preenchendo fraturas nos grãos de calcita (Figura 12A e 12B).

A hematita $\left[\mathrm{Fe}^{+3}{ }_{2} \mathrm{O}_{3}\right]$ ocorre principalmente nas bordas de oxidação tardias de minerais primários como a magnetita e encontra-se parcialmente substituída por oxi-hidróxidos, tipo goethita $\left[\mathrm{HFe}^{+3} \mathrm{O}_{2}\right]$ e lepidocrocita $\left[\mathrm{Fe}^{+3} \mathrm{O}(\mathrm{OH})\right]$. A goethita e os oxi-hidróxidos de Mn constituem diversos eventos de substituição e surgem no desenvolvimento tardio dos processos metassomáticos.

O intemperismo dos carbonatitos, além de concentrar a apatita, pode originar aluminofosfatos, ricos de ETR, e comuns aos do grupo da crandalita, goyazita, gorceixita, plumbogumita $\left[\mathrm{PbAl}_{3}\left(\mathrm{PO}_{4}\right)_{2}(\mathrm{OH})_{5}\right]$ e florencita $\left[\mathrm{CeAl}_{3}\left(\mathrm{PO}_{4}\right)_{2}(\mathrm{OH})\right]$. 

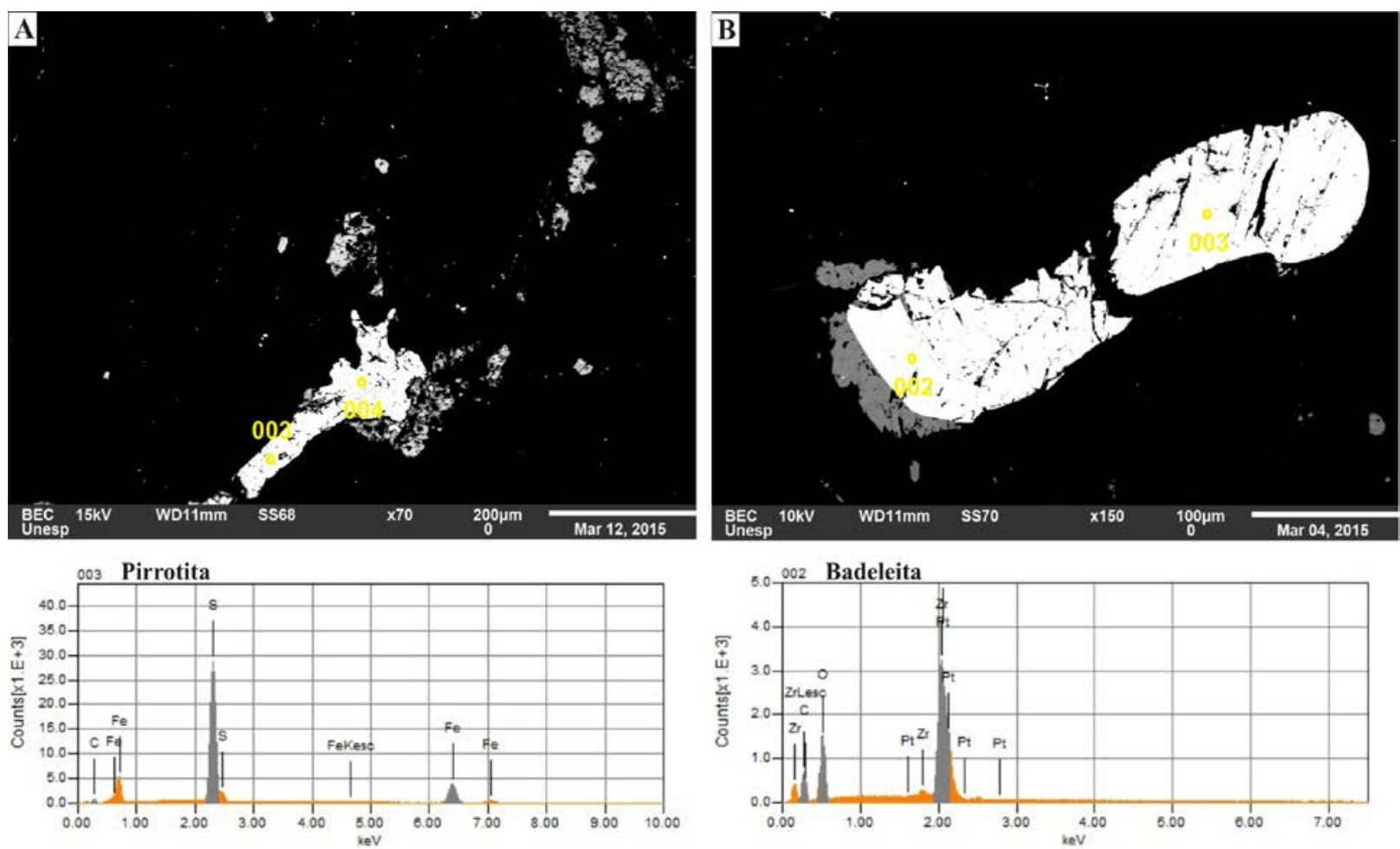

Figura 11. A) Imagem de microscópio eletrônico de varredura (elétrons retroespalhados) de cristal de pirrotita.

B) Cristal de badeleíta.
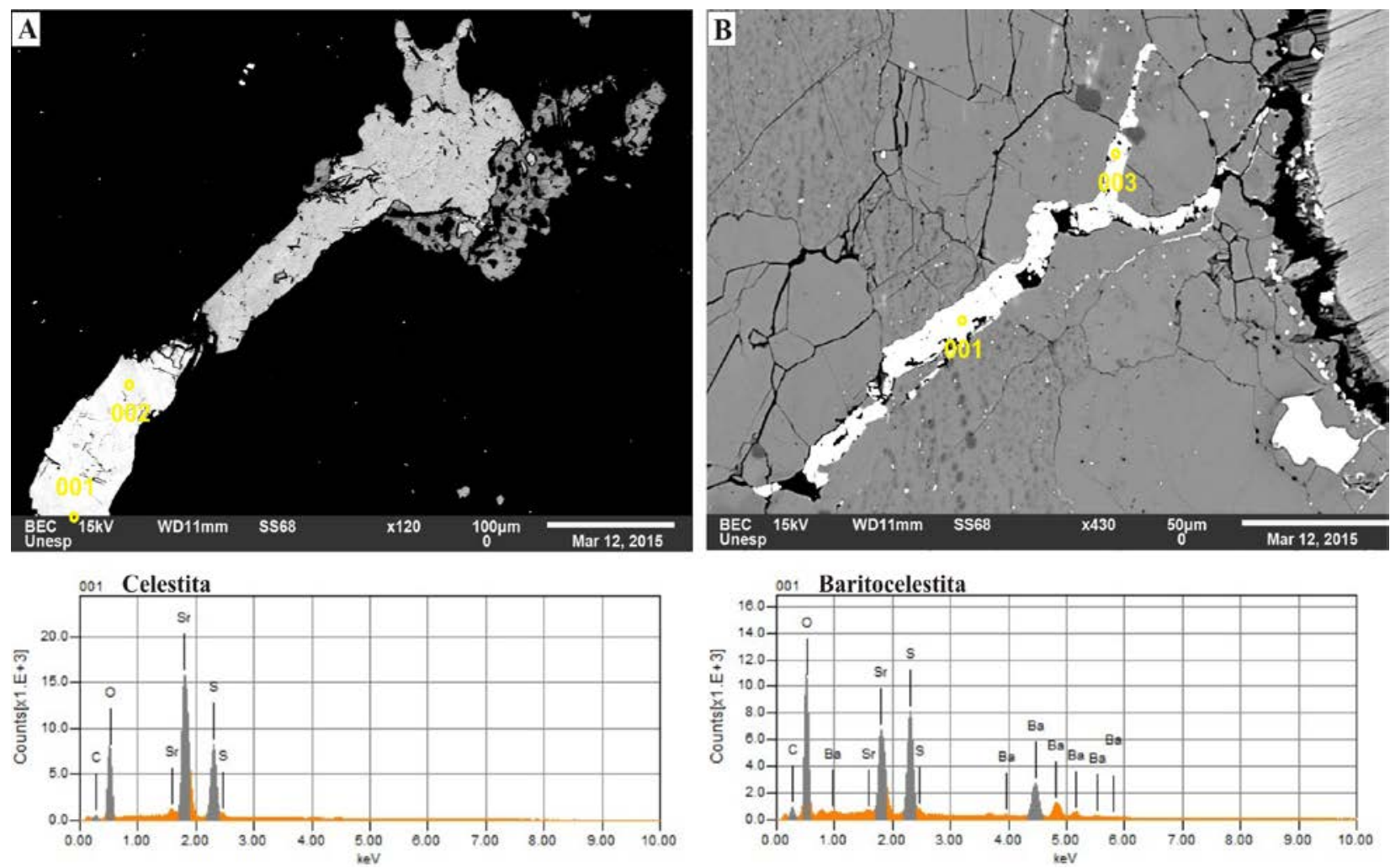

Figura 12. A) Imagem de microscópio eletrônico de varredura de cristal (elétrons retroespalhados) de celestita. B) Cristais de baritocelestita que preenchem fraturas na calcita.

\section{LITOGEOQUÍMICA}

Os trabalhos de litogeoquímica destas rochas carbonatíticas estão descritos em Silva et al. (1988), Liberal \& Cassola (1989), Gomes et al. (2001), Antonini et al. (2003) e Luciano (2016).
As 17 amostras analisadas de metacarbonatitos encontram-se na tabela 1 e estão identificadas nos diagramas pelos símbolos e abreviações das fácies correspondente. 
Tabela 1. Resultado de análises químicas de amostras das fácies do metacarbonatitos.

\begin{tabular}{|c|c|c|c|c|c|c|c|c|c|}
\hline \multirow{2}{*}{ Amostra } & \multirow{2}{*}{\begin{tabular}{|c|} 
(田) Ap MC. \\
RL-69-D
\end{tabular}} & \multicolumn{7}{|c|}{$(\bullet)$ Ol-Ap MC. } & \multirow{2}{*}{$\begin{array}{c}(\Delta) \text { Phl-Ap-Ol MC. } \\
\text { RL-68-B }\end{array}$} \\
\hline & & RL-2-B & RL-6-D & RL-2-D & RL-6-B & RL-66-B & RL-66-D & RL-67-B & \\
\hline $\mathrm{SiO}_{2}$ & 0,23 & 0,97 & 7,5 & 2,58 & 2,55 & 0,66 & 5,78 & 3,46 & 0,57 \\
\hline $\mathrm{TiO}_{2}$ & 0,06 & 0,02 & 0,11 & 0,14 & 0,08 & 0,04 & 0,07 & 0,19 & 0,03 \\
\hline $\mathrm{Al}_{2} \mathrm{O}_{3}$ & 0,12 & 0,24 & 0,86 & 0,26 & 0,25 & 0,11 & 0,6 & 0,11 & 0,06 \\
\hline $\mathrm{Fe}_{2} \mathrm{O}_{3}$ & 2,35 & 1,95 & 5,08 & 6,02 & 3,79 & 2,28 & 4,68 & 7,27 & 1,74 \\
\hline MnO & 0,09 & 0,1 & 0,16 & 0,15 & 0,15 & 0,13 & 0,14 & 0,25 & 0,1 \\
\hline $\mathrm{Cr}_{2} \mathrm{O}_{3}$ & $<0,01$ & $<0,01$ & $<0,01$ & $<0,01$ & $<0,01$ & $<0,01$ & $<0,01$ & $<0,01$ & $<0,01$ \\
\hline MgO & 1,79 & 2,12 & 7,41 & 3,17 & 4,19 & 2,37 & 6,17 & 3,67 & 2,29 \\
\hline $\mathrm{CaO}$ & 49,93 & 49,36 & 39 & 44,98 & 45,97 & 49,37 & 41,14 & 41,8 & 49,63 \\
\hline $\mathrm{Na}_{2} \mathrm{O}$ & 0,07 & 0,07 & 0,05 & 0,05 & 0,05 & 0,05 & 0,04 & 0,06 & 0,07 \\
\hline $\mathbf{K}_{2} \mathbf{O}$ & 0,02 & 0,03 & 0,28 & 0,05 & 0,07 & 0,04 & 0,21 & 0,02 & 0,03 \\
\hline $\mathbf{P}_{2} \mathbf{O}_{5}$ & 5,8 & 6,91 & 9,65 & 10,05 & 7,71 & 6,07 & 6,83 & 8,89 & 6,13 \\
\hline LOI & 37 & 35,47 & 25,11 & 29,17 & 31,71 & 35,5 & 29,88 & 29,55 & 36,44 \\
\hline TOTAL & 97,45 & 97,22 & 95,21 & 96,6 & 96,49 & 96,61 & 95,53 & 95,27 & 97,09 \\
\hline V & $<5$ & $<5$ & $<5$ & $<5$ & $<5$ & $<5$ & $<5$ & $<5$ & $<5$ \\
\hline Co & 5,5 & 5,5 & 14,1 & 20,7 & 10,5 & 5,9 & 15 & 12,1 & 5,4 \\
\hline $\mathrm{Ni}$ & 21 & 24 & 24 & 56 & 27 & 19 & 37 & 59 & 28 \\
\hline $\mathbf{C u}$ & 11 & 12 & 11 & 18 & 12 & 12 & 13 & 12 & 12 \\
\hline Zn & 25 & 27 & 51 & 38 & 26 & 27 & 40 & 82 & 23 \\
\hline Ga & $<0,1$ & $<0,1$ & $<0,1$ & $<0,1$ & $<0,1$ & $<0,1$ & $<0,1$ & 2,5 & $<0,1$ \\
\hline $\mathbf{R b}$ & 0,5 & 2,2 & 9,1 & 1,7 & 2,3 & 1,1 & 5,5 & 0,7 & 0,6 \\
\hline $\mathrm{Sr}$ & 15374 & 14793 & 11069 & 12537 & 13704 & 16299 & 11971 & 12361 & 15168 \\
\hline $\mathbf{Y}$ & 101,89 & 117,61 & 94,89 & 115,68 & 101,67 & 105,44 & 88,66 & 92,71 & 106,24 \\
\hline $\mathbf{Z r}$ & 15 & 102 & 232 & 281 & 409 & 93 & 304 & 314 & 21 \\
\hline $\mathbf{N b}$ & $<0,05$ & $<0,05$ & 0,22 & $<0,05$ & $<0,05$ & $<0,05$ & $<0,05$ & 1,29 & $<0,05$ \\
\hline Mo & $<2$ & $<2$ & $<2$ & $<2$ & $<2$ & $<2$ & $<2$ & $<2$ & $<2$ \\
\hline Pd (ppb) & $<5$ & $<5$ & $<5$ & $<5$ & $<5$ & $<5$ & $<5$ & $<5$ & $<5$ \\
\hline Ag & $*$ & $*$ & $*$ & $*$ & $*$ & $*$ & $*$ & $*$ & $*$ \\
\hline Sn & $<0,3$ & $<0,3$ & $<0,3$ & $<0,3$ & $<0,3$ & $<0,3$ & $<0,3$ & 0,4 & $<0,3$ \\
\hline Cs & $<0,05$ & 0,63 & 0,31 & 0,13 & 0,08 & $<0,05$ & 0,16 & $<0,05$ & $<0,05$ \\
\hline $\mathbf{B a}$ & 2103 & 1789 & 1876 & 1061 & 1177 & 1621 & 1914 & 925 & 3933 \\
\hline Hf & 0,34 & 1,48 & 3,54 & 3,86 & 5,39 & 1,22 & 3,54 & 2,99 & 0,42 \\
\hline $\mathbf{T a}$ & $<0,05$ & $<0,05$ & $<0,05$ & $<0,05$ & $<0,05$ & $<0,05$ & $<0,05$ & 0,14 & $<0,05$ \\
\hline $\mathbf{W}$ & $<0,1$ & 2 & 0,1 & 0,2 & 0,2 & $<0,1$ & 0,2 & $<0,1$ & 0,2 \\
\hline Pt (ppb) & $<5$ & $<5$ & $<5$ & $<5$ & $<5$ & $<5$ & $<5$ & $<5$ & $<5$ \\
\hline Au (ppb) & $<5$ & $<5$ & $<5$ & $<5$ & $<5$ & $<5$ & $<5$ & $<5$ & $<5$ \\
\hline Hg & $<0,05$ & $<0,05$ & $<0,05$ & $<0,05$ & $<0,05$ & $<0,05$ & $<0,05$ & $<0,05$ & $<0,05$ \\
\hline Tl & $<0,5$ & $<0,5$ & $<0,5$ & $<0,5$ & $<0,5$ & $<0,5$ & $<0,5$ & $<0,5$ & $<0,5$ \\
\hline Th & 5,7 & 11,6 & 17,9 & 17 & 13,5 & 9,1 & 10,3 & 12,8 & 7,6 \\
\hline $\mathbf{U}$ & 0,47 & 1,01 & 1,9 & 1,95 & 1,38 & 0,84 & 1,06 & 2,57 & 0,69 \\
\hline La & 835,5 & 883,9 & 673,7 & 852,4 & 761 & 805,7 & 672,5 & 689,2 & 884,3 \\
\hline $\mathrm{Ce}$ & 1727 & 1854 & 1499 & 1836 & 1634 & 1681 & 1463 & 1430 & 1838 \\
\hline Pr & 211,71 & 230,4 & 190,64 & 231,74 & 207,18 & 207 & 183,89 & 174,4 & 225,44 \\
\hline Nd & 842,5 & 928,8 & 774,5 & 937,4 & 828,4 & 825,1 & 735,5 & 677,2 & 895,1 \\
\hline Sm & 124,2 & 135,9 & 119,2 & 141,3 & 126,1 & 121,7 & 110,7 & 100,8 & 131,2 \\
\hline Eu & 31,35 & 35,38 & 30 & 34,44 & 30,93 & 30,52 & 27,76 & 24,86 & 32,48 \\
\hline Gd & 73,54 & 83,55 & 71,15 & 83,4 & 75,76 & 73,01 & 64,84 & 59,8 & 76,3 \\
\hline Tb & 6,81 & 7,78 & 6,58 & 7,75 & 7,17 & 6,87 & 6,13 & 5,69 & 7,17 \\
\hline Dy & 24,36 & 27,51 & 23,17 & 27,45 & 24,56 & 25,05 & 21,61 & 20,7 & 25,3 \\
\hline Ho & 3,27 & 3,68 & 3,06 & 3,62 & 3,25 & 3,35 & 2,86 & 2,91 & 3,37 \\
\hline Er & 6,36 & 7,27 & 5,92 & 7,09 & 6,33 & 6,64 & 5,63 & 5,78 & 6,59 \\
\hline $\mathbf{T m}$ & 0,62 & 0,7 & 0,55 & 0,71 & 0,61 & 0,64 & 0,52 & 0,62 & 0,63 \\
\hline Yb & 3,1 & 3,5 & 2,7 & 3,2 & 3 & 3,2 & 2,7 & 3,2 & 3,2 \\
\hline Lu & 0,34 & 0,41 & 0,32 & 0,39 & 0,35 & 0,36 & 0,31 & 0,4 & 0,36 \\
\hline
\end{tabular}

Legenda: (-) Não analisado; (*) Não reportado devido a interferentes; (<) Abaixo do limite de detecção; (>) Acima do limite de detecção. (田) Ap MC. Apatita Metacarbonatito, (0) Ol-Ap MC. Olivina-Apatita Metacarbonatito, $(\Delta)$ PhlAp-Ol MC. Flogopita-Apatita-Olivina Metacarbonatito, (+) Ol-Ap-Bt/Phl MC. Olivina-Apatita-Biotita/Flogopita Metacarbonatito e (x) MC. S. Metacarbonatito Silicificado (Luciano, 2016). 
Tabela 1. Resultado de análises químicas de amostras das fácies do metacarbonatitos (Continuação).

\begin{tabular}{|c|c|c|c|c|c|c|c|c|}
\hline \multirow{2}{*}{ Amostra } & \multicolumn{5}{|c|}{ (+) Ol-Ap-Bt/Phl MC. } & \multicolumn{3}{|c|}{ (X) MC. Silicificado. } \\
\hline & RL-1-B & RL-1-D & RL-3-A & RL-3-G & RL-69-B & RL-23-B & RL-65-B & RL-65-E \\
\hline $\mathrm{SiO}_{2}$ & 34,26 & 50,48 & 21,38 & 48,74 & 6,95 & 41,65 & $>90$ & 68,49 \\
\hline $\mathrm{TiO}_{2}$ & 0,34 & 0,39 & 1,19 & 0,24 & 0,22 & 0,12 & 0,03 & 0,13 \\
\hline $\mathrm{Al}_{2} \mathrm{O}_{3}$ & 10,4 & 20,76 & 5,79 & 7,07 & 0,8 & 0,29 & 0,83 & 0,27 \\
\hline $\mathrm{Fe}_{2} \mathrm{O}_{3}$ & 10,36 & 6,22 & 23,91 & 14,3 & 8,64 & 5,52 & 2,07 & 4,19 \\
\hline MnO & 0,29 & 0,07 & 0,26 & 0,43 & 0,13 & 0,12 & 0,06 & 0,02 \\
\hline $\mathrm{Cr}_{2} \mathrm{O}_{3}$ & $<0,01$ & $<0,01$ & $<0,01$ & $<0,01$ & $<0,01$ & $<0,01$ & $<0,01$ & $<0,01$ \\
\hline MgO & 11,86 & 3,35 & 5,7 & 2,71 & 6,15 & 0,08 & 0,15 & 0,24 \\
\hline $\mathrm{CaO}$ & 10,57 & 3,64 & 18,11 & 8,81 & 37,69 & 27,35 & 0,25 & 12,71 \\
\hline $\mathrm{Na}_{2} \mathrm{O}$ & 0,09 & 0,57 & 0,07 & 0,8 & 0,05 & 0,12 & 0,03 & 0,06 \\
\hline $\mathrm{K}_{2} \mathrm{O}$ & 3,49 & 1,07 & 1,06 & 1,27 & 0,05 & 0,02 & 0,06 & 0,05 \\
\hline $\mathbf{P}_{2} \mathbf{O}_{5}$ & 8,01 & 2,36 & 13,89 & 4,79 & 15,51 & 21,29 & 0,62 & 9,16 \\
\hline LOI & 6,24 & 10,71 & 4,94 & 6,56 & 19,2 & 0,77 & 1,1 & 0,84 \\
\hline TOTAL & 95,9 & 99,62 & 96,3 & 95,72 & 95,38 & 97,34 & - & 96,14 \\
\hline V & $<5$ & $<5$ & 70 & 14 & $<5$ & 41 & 63 & 25 \\
\hline Co & 129,7 & 68,7 & 43,3 & 19,4 & 24,6 & 10,3 & 4,3 & 11,8 \\
\hline $\mathrm{Ni}$ & 254 & 307 & 22 & 43 & 52 & 12 & 11 & 6 \\
\hline $\mathbf{C u}$ & 11 & 9 & 21 & 17 & 16 & 17 & 101 & 11 \\
\hline Zn & 1150 & 990 & 489 & 278 & 123 & 53 & 17 & 40 \\
\hline Ga & 5,5 & 18,3 & 1,5 & 12,8 & 1,7 & $<0,1$ & $<0,1$ & $<0,1$ \\
\hline $\mathbf{R b}$ & 118,3 & 242,2 & 32,8 & 26 & 1,6 & 1 & 2,5 & 1,2 \\
\hline Sr & 3098 & 1238 & 3948 & 2062 & 8465 & 5363 & 948 & 2842 \\
\hline $\mathbf{Y}$ & 109,8 & 51,16 & 147,21 & 74,62 & 97,62 & 160,81 & 68,85 & 94,35 \\
\hline $\mathbf{Z r}$ & 482 & 273 & 484 & 267 & 863 & 250 & $<10$ & 494 \\
\hline Nb & 26,23 & 12,4 & 10,18 & 7,37 & 0,59 & 1,51 & 0,43 & 0,27 \\
\hline Mo & $<2$ & $<2$ & $<2$ & $<2$ & $<2$ & 10 & 3 & 2 \\
\hline Pd (ppb) & $<5$ & $<5$ & $<5$ & $<5$ & $<5$ & $<5$ & $<5$ & $<5$ \\
\hline Ag & $*$ & $*$ & $*$ & $*$ & $*$ & $*$ & * & * \\
\hline Sn & 1,8 & 3,5 & 3,4 & 1 & 0,6 & 0,4 & $<0,3$ & $<0,3$ \\
\hline Cs & 7,31 & 81,04 & 1,11 & 0,13 & 0,09 & $<0,05$ & 0,14 & 0,07 \\
\hline Ba & 7978 & 7776 & 5537 & 3389 & 1462 & 244 & 1571 & 378 \\
\hline Hf & 6,06 & 5,58 & 8,65 & 6,61 & 10,77 & 2,74 & 0,07 & 5,73 \\
\hline Ta & 0,79 & 0,31 & 0,56 & 0,41 & $<0,05$ & 0,27 & $<0,05$ & $<0,05$ \\
\hline $\mathbf{W}$ & 0,9 & $<0,1$ & 1,3 & 1,7 & $<0,1$ & 0,1 & 0,7 & 0,4 \\
\hline Pt (ppb) & $<5$ & $<5$ & $<5$ & $<5$ & $<5$ & $<5$ & $<5$ & $<5$ \\
\hline Au (ppb) & $<5$ & $<5$ & 8 & 10 & $<5$ & $<5$ & $<5$ & $<5$ \\
\hline Hg & 0,13 & 0,05 & 0,1 & $<0,05$ & $<0,05$ & $<0,05$ & $<0,05$ & $<0,05$ \\
\hline Tl & $<0,5$ & 0,5 & $<0,5$ & $<0,5$ & $<0,5$ & $<0,5$ & $<0,5$ & $<0,5$ \\
\hline Th & 47,4 & 36,5 & 19,9 & 128,1 & 18,3 & 25,3 & 1,6 & 15 \\
\hline $\mathbf{U}$ & 7,16 & 6,93 & 2,23 & 24,35 & 1,92 & 4,37 & 0,65 & 2,29 \\
\hline La & 1003 & 642,8 & 1093 & 593,3 & 678,1 & 1537 & 727,7 & 755,9 \\
\hline $\mathrm{Ce}$ & 2992 & 1320 & 2408 & 1261 & 1528 & 3280 & 1353 & 1626 \\
\hline Pr & 287,89 & 142,43 & 303,62 & 142,72 & 198,89 & 400,42 & 151,07 & 203,58 \\
\hline Nd & 1117 & 500,7 & 1231 & 519,8 & 815,4 & 1562 & 563,1 & 821 \\
\hline Sm & 163,3 & 64,6 & 186,3 & 71,3 & 125,7 & 225,2 & 77,8 & 125 \\
\hline Eu & 38,5 & 15,6 & 45,59 & 14,78 & 31,65 & 55,2 & 19,97 & 30,72 \\
\hline Gd & 89,16 & 33,74 & 112,63 & 41,66 & 75,93 & 127,69 & 44,62 & 72,87 \\
\hline Tb & 8,61 & 3,25 & 10,45 & 4,07 & 6,93 & 11,89 & 4,28 & 6,88 \\
\hline Dy & 29,13 & 11,87 & 35,71 & 15,79 & 24,06 & 40,57 & 15,34 & 24,09 \\
\hline Ho & 3,75 & 1,62 & 4,69 & 2,35 & 3,18 & 5,25 & 2,13 & 3,08 \\
\hline Er & 7,3 & 3,61 & 8,89 & 5,48 & 6,05 & 10,36 & 4,53 & 5,78 \\
\hline $\mathrm{Tm}$ & 0,71 & 0,4 & 0,86 & 0,65 & 0,58 & 1,04 & 0,52 & 0,58 \\
\hline Yb & 3,4 & 2,4 & 3,9 & 4,1 & 2,6 & 5,1 & 2,9 & 2,6 \\
\hline Lu & 0,38 & 0,32 & 0,47 & 0,56 & 0,31 & 0,62 & 0,39 & 0,3 \\
\hline
\end{tabular}

Legenda: (-) Não analisado; (*) Não reportado devido a interferentes; (<) Abaixo do limite de detecção; (>) Acima do limite de detecção. (田) Ap MC. Apatita Metacarbonatito, ( O) Ol-Ap MC. Olivina-Apatita Metacarbonatito, $(\Delta)$ PhlAp-Ol MC. Flogopita-Apatita-Olivina Metacarbonatito, (†) Ol-Ap-Bt/Phl MC. Olivina-Apatita-Biotita/Flogopita Metacarbonatito e (X) MC. S. Metacarbonatito Silicificado (Luciano, 2016). 
A partir da distribuição química dos teores dos Elementos Maiores observados no diagrama C-M-F [CaO-MgO- $\left.\left(\mathrm{FeO}_{\mathrm{t}}+\mathrm{MnO}\right)\right]$ de Woolley (1982), da figura 13, pode-se definir para as amostras: 07 calciocarbonatitos $(>80 \%$ $\mathrm{CaO}), 03$ magnesiocarbonatitos $(\mathrm{MgO}>\mathrm{FeO}+$ $\left.\mathrm{Fe}_{2} \mathrm{O}_{3}+\mathrm{MnO}\right)$ e 07 ferrocarbonatitos ( $\mathrm{FeO}+$ $\mathrm{Fe}_{2} \mathrm{O}_{3}+\mathrm{MnO}>\mathrm{MgO}$ ).

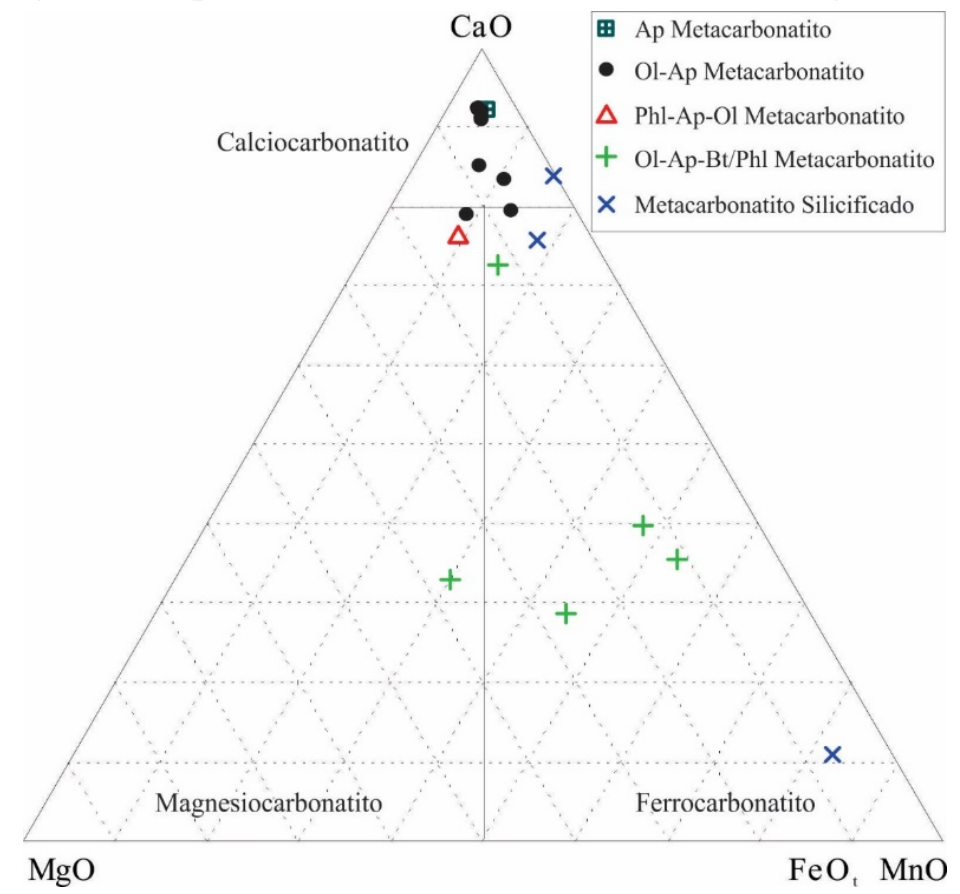

Figura 13. Diagrama C-M-F [CaO-MgO- $\left.\left(\mathrm{FeO}_{\mathrm{t}}+\mathrm{MnO}\right)\right]$ de classificação de rochas metacarbonatíticas. Legenda: (田) Ap MC. Apatita Metacarbonatito, ( O ) Ol-Ap MC. Olivina-Apatita Metacarbonatito, ( $\Delta$ ) Phl-Ap-Ol MC. FlogopitaApatita-Olivina Metacarbonatito, (+) Ol-Ap-Bt/Phl MC. Olivina-Apatita-Biotita/Flogopita Metacarbonatito e (X) MC. S. Metacarbonatito Silicificado.

As amostras representativas dos calciocarbonatitos apresentam valores de $(\mathrm{CaO})$ entre (39-49,93\%) e distribuem-se de forma homogênea no diagrama, com uma dispersão mediana, marcado pela presença de $\left(\mathrm{FeO}_{\mathrm{t}}+\right.$ $\mathrm{MnO})$ em relação ao (MgO). Este resultado deve-se à presença de magnetita e produtos resultantes da sua alteração com as disseminações de hidróxidos e óxidos de ferro $\left(\mathrm{FeO}^{\mathrm{t}}<7,27 \%\right)$ e raramente de manganês $(\mathrm{MnO}<0,25 \%)$. O magnésio é função da presença de olivina e do seu produto de alteração, a serpentina, com valores elevados de ( $\mathrm{MgO}<4,19 \%)$. As amostras distribuídas próximas aos limites com os ferrocarbonatitos e magnesiocarbonatitos apresentam leve redução $(\mathrm{CaO})$ e aumento de $\left(\mathrm{FeO}_{\mathrm{t}}+\mathrm{MnO}\right)$ e $(\mathrm{MgO})$.

As amostras com assinatura composicional dos ferrocarbonatitos traduzem o enriquecimento relativo em magnetita e produtos resultantes da sua alteração, com valores entre (6,17-8,64\%) próximo da fronteira com os calciocarbonatitos. $\mathrm{O}\left(\mathrm{FeO}_{\mathrm{t}}\right)$ nos ferrocarbonatitos concentra-se entre os valores (10,3623,91\%). O valor de $\left(\mathrm{FeO}_{\mathrm{t}}\right)$ extrema-mente elevado no metacarbonatito silicificado deve-se à presença de valores altos de $\left(\mathrm{SiO}_{2}>90 \%\right)$.

As amostras com assinatura composicional dos magnesiocarbonatito apresentam dados que se distribuem próximo da fronteira com os calciocarbonatitos, com valores crescentes de (MgO) em detrimento ao $(\mathrm{CaO})$ e traduz o enriquecimento relativo em olivina e produtos da sua alteração.

A partir dos parâmetros estabelecidos por Woolley \& Kempe (1989), em que calciocarbonatitos se caracterizam por apresentar a razão $\mathrm{CaO} /\left(\mathrm{CaO}+\mathrm{FeO}_{\mathrm{t}}+\mathrm{MgO}\right)>0,80$, ferrocarbonatito por possuir $\left(\mathrm{FeO}_{\mathrm{t}}+\mathrm{MnO}\right)>$ $\mathrm{MgO}$, magnesiocarbonatito por ser $\mathrm{MgO}>$ $\left(\mathrm{FeO}_{\mathrm{t}}+\mathrm{MnO}\right)$ e natrocarbonatito por exibir $\left(\mathrm{Na}_{2} \mathrm{O}+\mathrm{K}_{2} \mathrm{O}\right)>\left(\mathrm{CaO}+\mathrm{MgO}+\mathrm{FeO}^{\mathrm{t}}\right)$, foi possível estabelecer as seguintes relações: 09 amostras classificadas como calciocarbonatito, 10 amostras classificadas como ferrocarbonatito, 07 amostras classificadas como magnesiocarbo-natitos e nenhuma como natrocarbonatito. A distribuição de Elementos Maiores versus $(\mathrm{CaO})$ está expressa nos diagramas do tipo Harker (Figura 14), a partir do cálcio, um elemento de participação representativa na evolução e diferenciação deste conjunto litológico. 

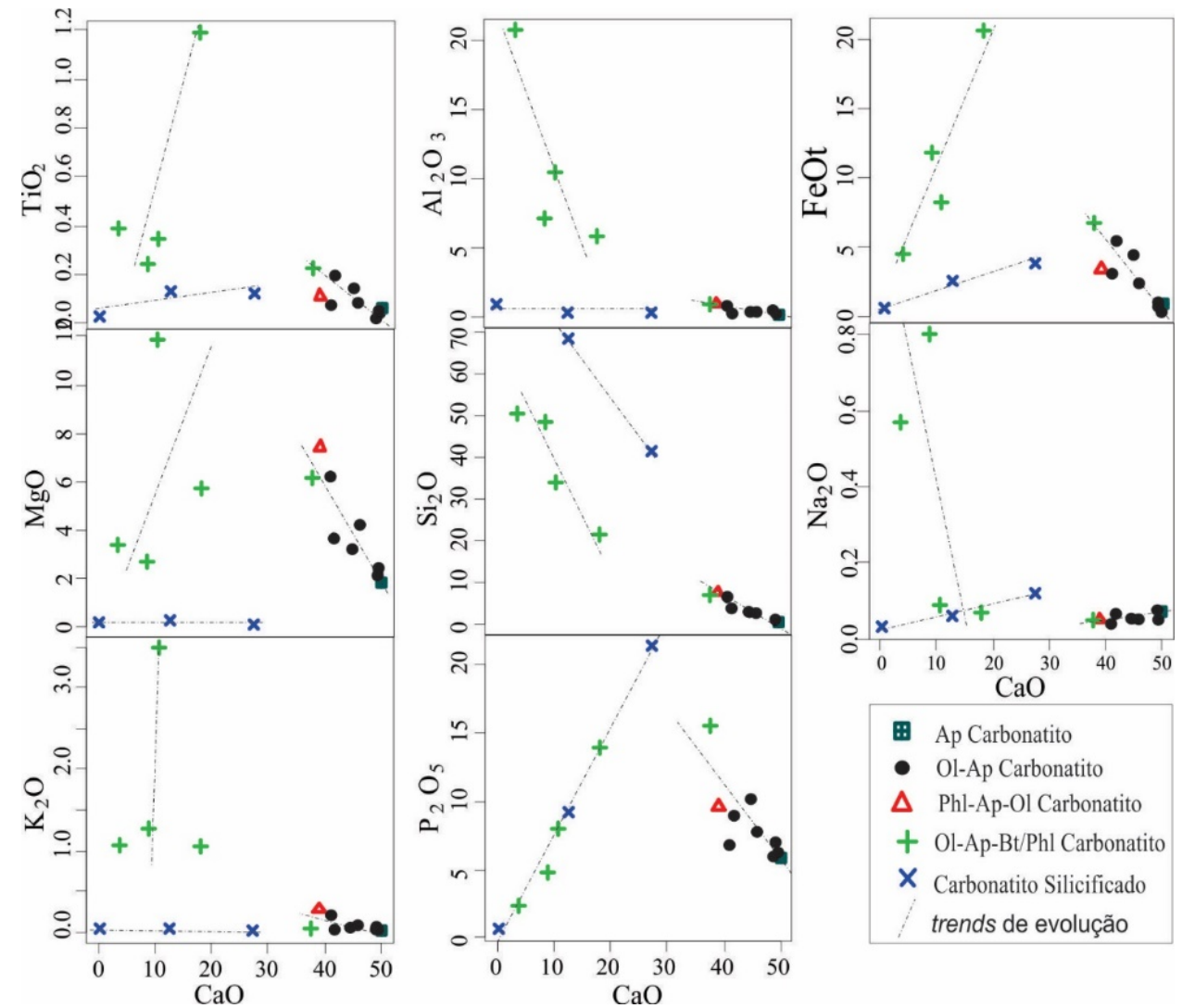

Figura 14. Diagramas de elementos maiores das amostras de carbonatito. Legenda: (由) Ap MC. Apatita Metacarbonatito, (O) Ol-Ap MC. Olivina-Apatita Metacarbonatito, ( $\Delta$ ) Phl-Ap-Ol MC. Flogopita-Apatita-Olivina Metacarbonatito, (+) Ol-Ap-Bt/Phl MC. Olivina-Apatita-Biotita/Flogopita Metacarbonatito e (X) MC. S. Metacarbonatito Silicificado.

As amostras de metacarbonatitos apresentam grande variação composicional em relação a $\mathrm{SiO}_{2} \quad(0,23-95,00 \%), \quad \mathrm{Al}_{2} \mathrm{O}_{3} \quad(0,06-0,76 \%)$, $\mathrm{Fe}_{2} \mathrm{O}_{3}$ (1,74-23,91\%), MgO (0,08-11,86\%), $\mathrm{CaO}(0,25-49,94 \%)$ e $\mathrm{P}_{2} \mathrm{O}_{5} \quad(0,62-21,29 \%)$, além de baixos teores de $\mathrm{TiO}_{2}(0,02-1,19 \%)$, $\mathrm{MnO}(0,02-0,43 \%), \quad \mathrm{Cr}_{2} \mathrm{O}_{3}(<0,01 \%), \quad \mathrm{Na}_{2} \mathrm{O}$ (0,03-0,80\% e $\mathrm{K}_{2} \mathrm{O}(0,77-3,49 \%)$.

Em relação à sílica, os apatita metacarbonatitos possuem baixos teores de $(0,23 \%)$ e o olivina-apatita metacarbonatitos teores entre (0,66-5,78\%) e são identificados pelos baixos teores $\mathrm{Al}_{2} \mathrm{O}_{3}, \mathrm{MgO}, \mathrm{FeO}, \mathrm{K}_{2} \mathrm{O}$ e $\mathrm{Na}_{2} \mathrm{O}$ e elevados de $\mathrm{CaO}$ (49,93-41,14\%), reflexo da mineralogia primária: carbonato calcítico e subordinadamente óxidos, fosfatos, sulfetos e silicatos ferromagnesianos.

O ferro é observado principalmente a partir do aumento de sílica e consequentemente dos demais óxidos, levando a um aumento na porcentagem de minerais ferromagnesianos, diversificando os subtipos litológicos. Observase que as rochas metacarbonatíticas apresentam uma tendência composicional que se inicia no vértice do cálcio e se dirige para os domínios dos metacarbonatitos magnésio-ferruginosos $\left(\mathrm{FeO}_{\mathrm{t}}\right)$, sugerindo uma evolução no sentido das assembleias dominantemente calcíticas passando cada vez mais para dolomíticas até anqueríticas. Portanto, destaca-se uma diferenciação química, em que os calciocarbonatitos são menos diferenciados, seguidos dos magnesiocarbonatitos e no final os ferrocarbonatitos são os mais diferenciados.

O magnésio apresenta um crescimento acentuado dos teores para as fácies que apresentam assembleias minerais com maior presença de olivina e flogopita.

O sódio apresenta valores baixos para todas as amostras, enquanto o potássio cresce representativamente para as fácies metacarbonatíticas com presença principalmente de flogopita.

O manganês ocorre em teor baixo e seus valores mais expressivos apresentam significativa correlação positiva com o ferro.

Os conteúdos de fósforo são elevados em função da presença de quantidades apreciáveis de apatita.

A correlação inversa pode ser observada 
entre $\mathrm{CaO}$ versus $\mathrm{TiO}_{2}, \mathrm{Al}_{2} \mathrm{O}_{5}, \mathrm{FeO}_{\mathrm{t}}, \mathrm{MgO}$ e $\mathrm{P}_{2} \mathrm{O}_{5}$ para o olivina-apatita metacarbonatito, o que evidencia a variação no conteúdo de minerais opacos, flogopita, serpentina, anfibólio e apatita neste litotipo. Como consequência do aumento de silicatos e fosfato, ocorre a diminuição de carbonato, que resulta na correlação inversa entre $\mathrm{CaO}$ e $\mathrm{SiO}_{2}$.

As amostras do olivina-apatitabiotita/flogopita metacarbonatito apresentam uma correlação direta entre $\mathrm{CaO}$ versus $\mathrm{TiO}_{2}$, $\mathrm{FeO}_{\mathrm{t}}, \mathrm{MgO}, \mathrm{K}_{2} \mathrm{O}$ e $\mathrm{P}_{2} \mathrm{O}_{5}$, que se deve à variação na composição de minerais opacos, serpentina e apatita. Em relação ao olivina-apatita metacarbonatito há a correlação inversa entre $\mathrm{CaO}$ versus $\mathrm{Al}_{2} \mathrm{O}_{3}, \mathrm{SiO}_{2}$ e $\mathrm{Na}_{2} \mathrm{O}$, que se deve ao aumento de flogopita, na sua composição.

A correlação direta entre $\mathrm{CaO}$ versus $\mathrm{TiO}_{2}$, $\mathrm{FeO}_{\mathrm{t}}, \mathrm{Na}_{2} \mathrm{O}$ e $\mathrm{P}_{2} \mathrm{O}_{5}$ observados nos metacarbonatito silicificado está associada à variação na composição de minerais opacos, micas e apatita e é inversa entre o $\mathrm{CaO}$ e $\mathrm{SiO}_{2}$, coerente com o processo de silicificação dos metacarbonatitos.

A distribuição dos teores de Elementos Menores e Traços da figura 15 evidenciam trends evolutivos, a partir da disposição linear de elemento em um mesmo subtipo carbonatítico. São observados valores elevados em relação à média de níquel (6-307ppm) e cobre (9-101ppm), enquanto são baixos para zircônio (5-863ppm), nióbio (0,03-26,23ppm) e molibdênio (1-10ppm).
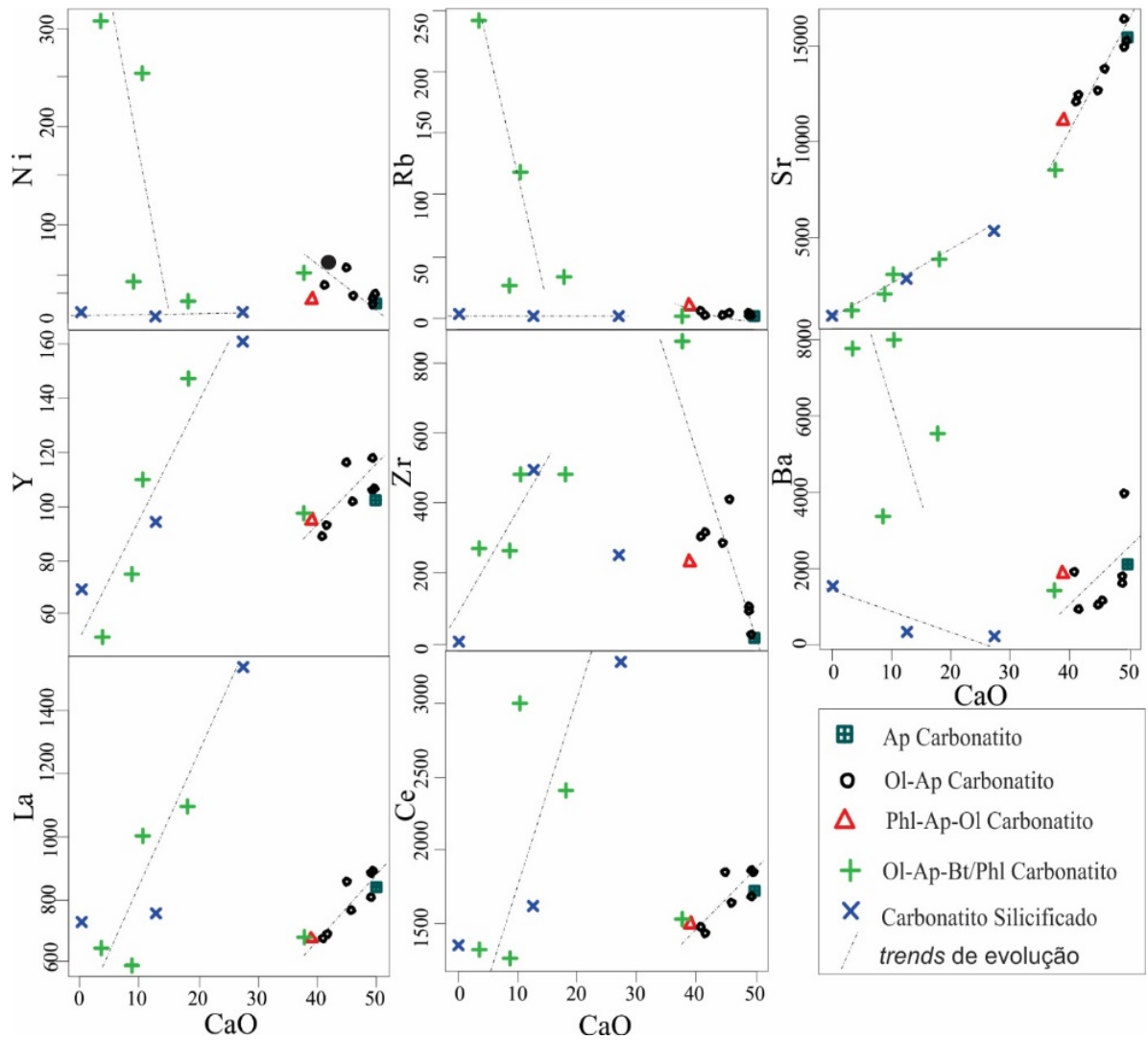

Figura 15. Diagramas binários de elementos traços. Legenda: (田) Ap MC. Apatita Metacarbonatito, ( O ) Ol-Ap MC. Olivina-Apatita Metacarbonatito, ( $\Delta$ ) Phl-Ap-Ol MC. Flogopita-Apatita-Olivina Metacarbonatito, (+) Ol-ApBt/Phl MC. Olivina-Apatita-Biotita/Flogopita Metacarbonatito e ( $x$ ) MC. S. Metacarbonatito Silicificado.

Nos diagramas de rubídio e bário evidenciam-se que os teores mais altos ocorrem nos olivina-apatita-biotita/flogopita metacarbonatito, devido a associação com potássio das biotitas e é caracterizado por uma redução dos valores, para os litotipos carbonatíticos de uma mesma associação mais enriquecidas em $\mathrm{CaO}$ e para as associações menos diferenciadas e enriquecidas em cálcio. Os teores elevados de Ba entre (1.462-7.978ppm) estão diretamente correlacionados ao aumento no conteúdo de sulfatos (baritocelestita).

Os elevados teores de estrôncio entre (1.2388.465ppm) deve-se à presença de sulfatos (baritocelestita e celestita) e flogopita. Os diagramas de ítrio, zircônio, lantânio e cério apresentam valores elevados e definem duas tendências crescentes de distribuição que apresentam: uma com valores mais concentrados a partir das fácies mais diferenciadas constituídas 
por olivina-apatita- biotita/flogopita metacarbonatito e metacarbonatito silicificado e a segunda os valores são menores nas fácies menos evoluídas e ocorrem nos metacarbonatito, olivina-apatita metacarbonatito e flogopita-apatita-olivina metacarbonatito.

A razão é do maior fracionamento magmático, com consequente aumento das suas concentrações ( $\mathrm{Y}, \mathrm{Zr}$, La e $\mathrm{Ce}$ ) nos líquidos mais diferenciados finais, resultado do empobrecimento de flogopita, pseudomorfo de olivina e minerais opacos. Estes elementos associam-se mais diretamente à monazita, aumentando a concentração dos mesmos quanto maior o percentual desses minerais na rocha, contudo devem associar-se também aos
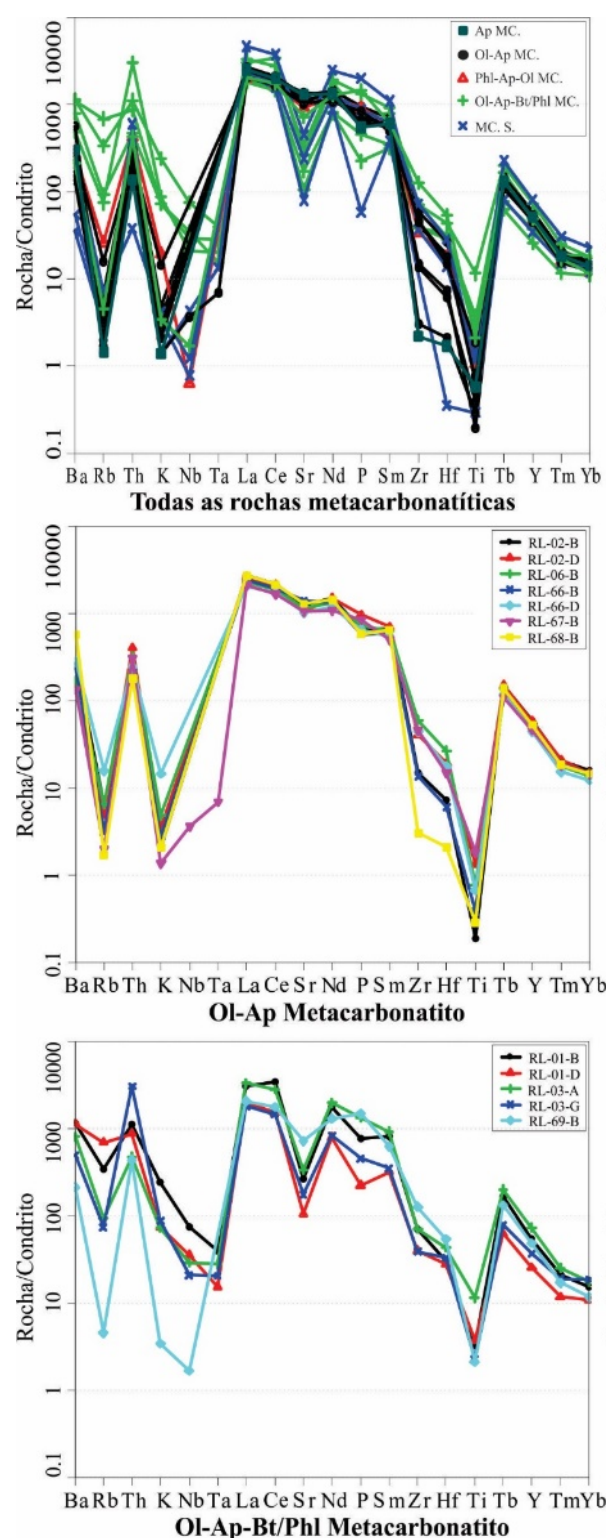

carbonatos. No caso da presença de badeleíta nas rochas as concentrações de zircônio são marcantes.

A distribuição dos teores de Elementos Traços identificadas nos diagramas de distribuição multielementar normalizado para meteorito condrito (Thompson, 1982), visto na figura 16, as rochas apresentam valores negativos, como forte fracionamento de rubídio, potássio, nióbio e titânio, consequência da ampla variação química e resultado da ocorrência de flogopita e minerais opacos.

Uma das maneiras de se interpretar as fortes anomalias negativas é como feições de estágios magmáticos mais diferenciados a partir de processos de cristalização fracionada.
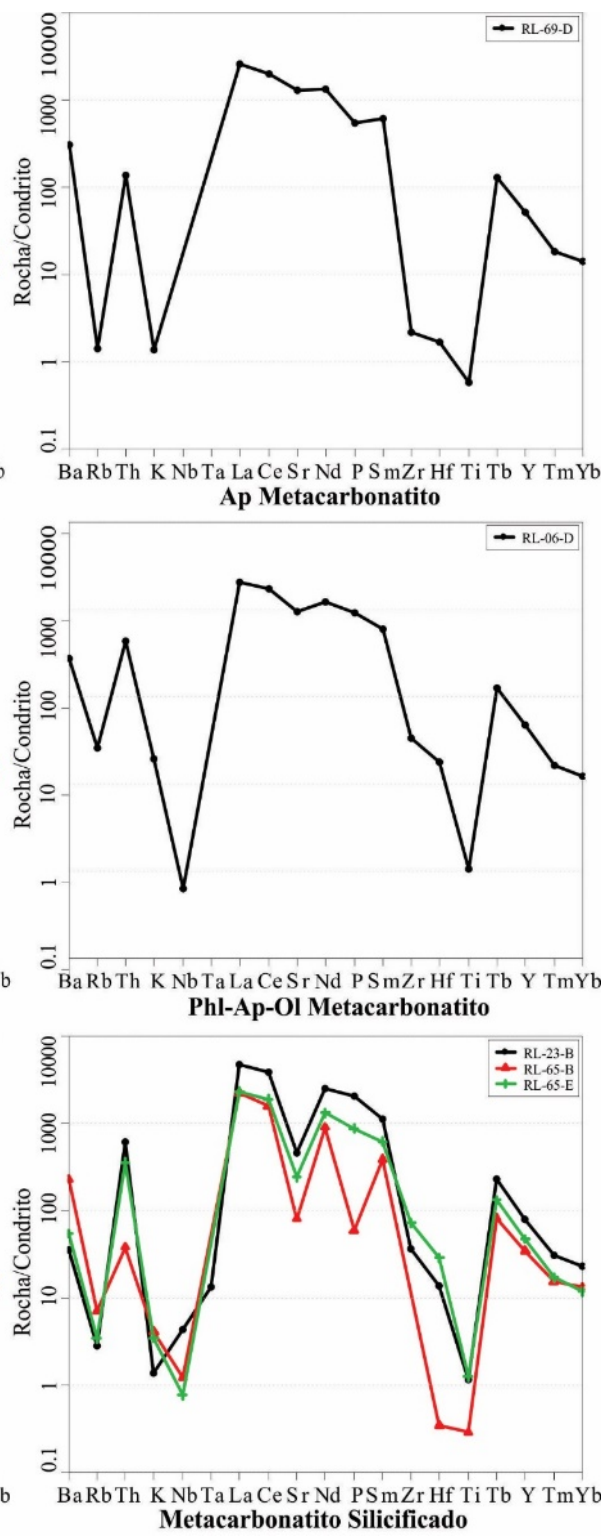

Figura 16. Diagrama de distribuição multielementar dos corpos carbonatíticos para os elementos terras raras, normalizados para condrito de Thompson (1982). Legenda: (田) Ap MC. Apatita Metacarbonatito, (O) Ol-Ap MC. Olivina-Apatita Metacarbonatito, ( $\Delta)$ Phl-Ap-Ol MC. Flogopita-Apatita-Olivina Metacarbonatito, (+) Ol-ApBt/Phl MC. Olivina-Apatita-Biotita/Flogopita Metacarbonatito e (X) MC. S. Metacarbonatito Silicificado. 
Os padrões dos elementos incompatíveis definidos para todas as litologias são caracterizados por anomalias positivas de tório que provavelmente prendem-se a possíveis cristais de pirocloro e fluorcarbonatos de terras raras, nos quais este elemento se encontra possivelmente alojado na estrutura cristalina. $\mathrm{O}$ empobrecimento titânio é resultado da pequena importância ou ausência de fases titanadas na evolução do conjunto de fácies carbonatíticas.

Nas fácies olivina-apatita-biotita/flogopita metacarbonatito e metacarbonatito silicificado são observadas anomalias negativas registradas de estrôncio, que estaria alojado na estrutura dos carbonatos substituindo o cálcio. As anomalias negativas de fósforo encontram-se diretamente evidenciadas por uma redução de apatitas e diversificação dos minerais ferromagnesianos.

A assinatura dos elementos mais incompatíveis (LILE), como o $\mathrm{Ba}, \mathrm{Rb}$ e $\mathrm{K}$, mostram elevados conteúdos em bário, pronunciadas anomalias negativas em rubídio e em potássio que evidenciam um leve enriquecimento para as fases carbonatíticas mais diferenciadas. O bário apresenta o maior grau de enriquecimento dentre os LILE e devese às fases do grupo do pirocloro.

Anomalias negativas de $\mathrm{Rb}$ e $\mathrm{K}$ e mais suaves de $\mathrm{Zr}$ ressaltam nas distintas variedades petrográficas da paragênese metacarbonatítica, destituída de feldspatos e constituída de óxidos de $\mathrm{Fe}-\mathrm{Ti}$, flogopita e badeleíta. O fracionamento do fósforo, estrôncio, rubídio e bário está associado principalmente ao porcentual de apatita, carbonato e flogopita na rocha, sendo uma possível consequência do processo magmático de cristalização fracionada e da diferenciação magmática. O mesmo raciocínio pode ser empregado quanto ao fracionamento do zircônio e do háfnio, que estão associados à cristalização badeleíta.

$\mathrm{O}$ forte fracionamento e enriquecimento em tório e térbio se deve provavelmente a variação composicional e química de apatita e minerais opacos para o Th e apatita e carbonatos para o Te. O fracionamento do nióbio e do tálio relaciona-se ao conteúdo de minerais opacos, principalmente a porcentagem de ilmenita e pirita, respectivamente.

No geral, os espectros multielementares evidenciam variações gradativas de enriquecimento de minerais silicáticos ferromagne- sianos, desde os calciocarbonatitos, magnésiocarbonatitos aos ferrocarbonatitos e ilustram um possível comportamento geoquímico levemente heterogêneo de todos os elementos estudados, o que sugere uma filiação magmática comum associada a processos de diferenciação magmatica por segregação mineral.

A distribuição química dos teores de Elementos Terras Raras (ETR), visto nos diagramas da figura 17 , de distribuição multielementar normalizado para condrito (Boynton, 1984), apresentam no geral uma distribuição com teores relativamente paralelos, bastante inclinados, ausência de anomalia do Eu e os valores da razão de $\left(\mathrm{Eu} / \mathrm{Eu}^{*}\right)$ próximos a 1 , característicos dos carbonatitos.

As curvas de distribuição são simétricas e evidenciam um aumento progressivo nos teores absolutos dos ETR para os ferrocarbonatitos e apresentam leve decréscimo para os magnesiocarbonatitos e calciocarbonatitos, que evoluem seguindo a mesma sequência registrada junto aos demais elementos incompatíveis.

O somatório do conteúdo de elementos terras raras (ETR) nas amostras variam entre (2.748,08-7.418,05ppm). Isso se deve à elevada concentração de apatitas, bem como ao conteúdo de carbonato. Exibem forte fracionamento entre os elementos terras raras leves (ETRL), com valores entre (2.6012,90$7.059,82 \mathrm{ppm}$ ), e pesados (ETRP), com valores entre (105,97-358,23ppm), verificável também pelos valores da razão $\Sigma E T R L / \Sigma E T R P$, entre (15,74-25,35ppm) e pelos valores da razão $(\mathrm{La} / \mathrm{Lu})_{\mathrm{N}}$, entre $(110,06-274,19 \mathrm{ppm})$, evidenciando alto fracionamento entre ETRL/ETRP.

Com relação aos elementos terras raras, verifica-se que os teores de lantânio (593,3$1.537 \mathrm{ppm})$ e cério (1.261-3.280ppm) estão dentro dos padrões esperados para rochas metacarbonatíticas.

Os ferrocarbonatitos denunciam padrões mais variáveis com pequenos declives negativos mais acentuados e transições, fato que deveria tipificar maior fracionamento para este conjunto.

Não ocorrem anomalias expressivas de cério, exceto no caso da amostra ferrocarbonatito, que apresenta discreta anomalia positiva de cério, em função do teor de apatita relativamente moderado a baixo (18\%), e muito provavelmente elevado conteúdo de monazita. 

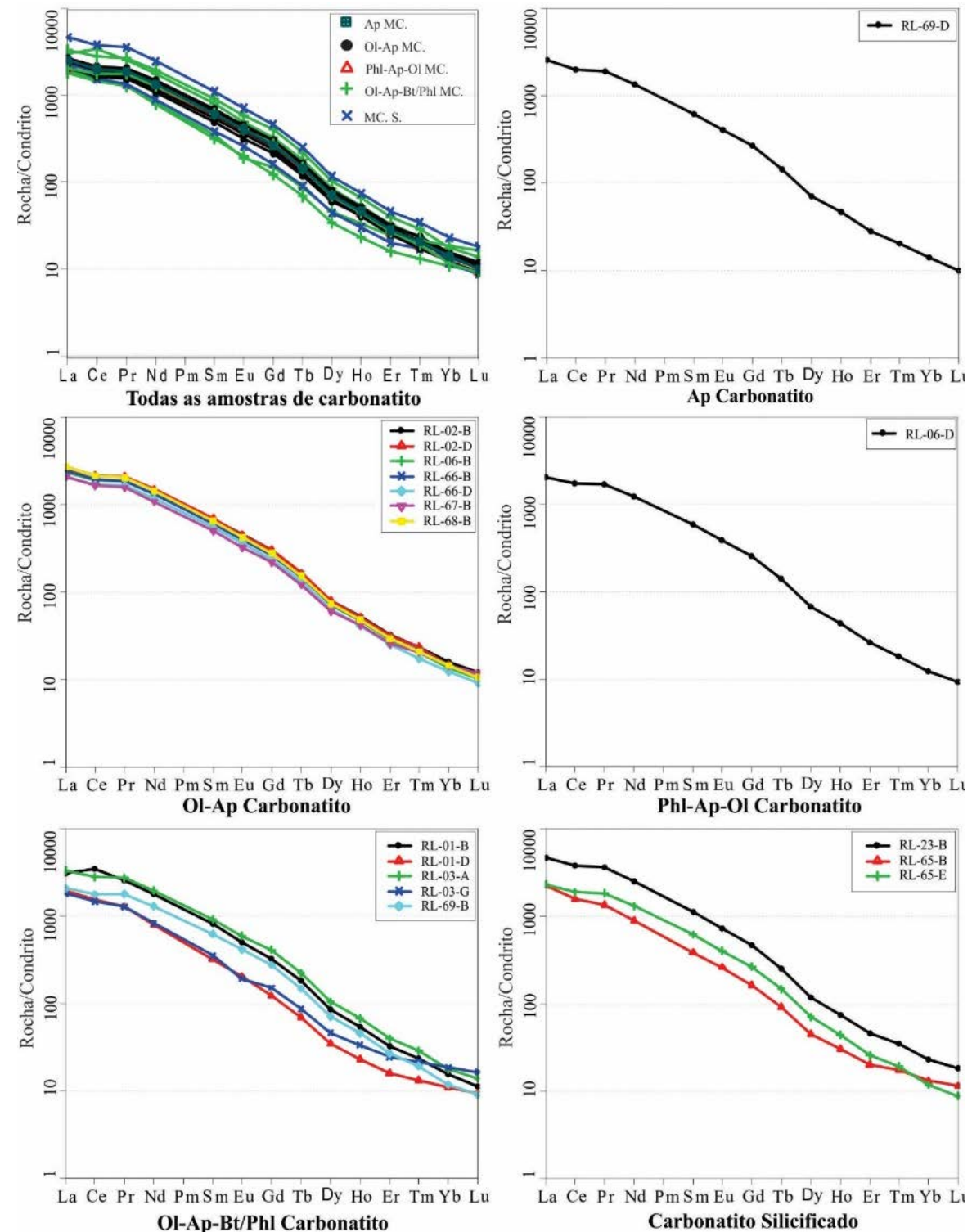

Figura 17. Diagrama de distribuição multielementar das rochas metacarbonatíticas para os elementos traços e terras raras, normalizados para meteorito condrito de (Boynton, 1984). Legenda: (田) Ap MC. Apatita Metacarbonatito, (O) Ol-Ap MC. Olivina-Apatita Metacarbonatito, $(\boldsymbol{\Delta})$ Phl-Ap-Ol MC. Flogopita-Apatita-Olivina Metacarbonatito, $(+)$ Ol-Ap-Bt/Phl MC. Olivina-Apatita-Biotita/Flogopita Metacarbonatito e (X) MC. S. Metacarbonatito Silicificado.

Todos estes comportamentos são compatíveis com a distribuição e abundância relativa das fases portadoras de ETR observadas em petrografia, assim como a sua natureza composicional, avaliada com base em análises químicas pontuais.

Os elevados teores em ETR e o pronunciado fracionamento ETRL/ETRP das rochas carbonatíticas parecem estar relacionados com processos de natureza hidrotermal responsáveis pela formação das fases oxidadas, flúorfosfatadas e carbonatadas portadoras de ETR, eventualmente reforçada por efeitos intempéricos.

\section{CONCLUSÕES}

As rochas do Complexo Metacarbonatítico de Angico dos Dias são lavradas pela Mineração Galvani para minerais fosfatados e são constituídas por metacarbonatitos primários, metassienitos variados, metapiroxenitos, metadioritos alcalinos, tremolititos, biotitito, metalamprófiros, fenitos e apatitito que constituem um espesso manto de intemperismo de alteração dos metacarbonatitos primários e geram os depósitos de fosfato residual. As associações minerais ígneas anidras e metamórficas de alto grau de idade paleoproterozoica apresentam-se 
associadas a processos tardi-magmáticos hidrotermais e à superposição de caráter retrometamórficas de paragêneses em fácies xisto-verde alto de idade neoproterozoica.

As rochas são classificadas dominantemente como calciocarbonatito e constituídas principalmente por calcita e apatita e subordinado dolomita, olivina, flogopita e magnetita.

A variação no conteúdo de apatita, minerais ferromagnesianos e magnetita, definem um acamamento magmático cumulático, constituindo a diferenciação magmática o principal mecanismo responsável pela evolução do magma.

Este processo permite individualizar cinco litotipos petrográficos carbonatíticos: o apatita metacarbonatito; olivina-apatita metacarbonatito; flogopita-apatita-olivina metacarbonatito; olivina-apatita-biotita/flogopita metacarbonatito e metacarbonatito silicificado.

Os dados petrográficos e de química mineral apontam a presença de calcita com exsolução de dolomita, fluorapatitas, pseudomorfos de olivina alteradas para serpentina, tremolita, antofilita e magnetita, flogopitas, badeleíta, exsolução de ilmenita em magnetitas que se altera para hematita, pirrotita, pirita, calcopirita, sulfatos como celestita e baritocelestita e oxihidróxidos do tipo goethita e lepidocrocita.

O intemperismo dos carbonatitos encontrase associado com as carapaças ferruginosas e/ou silicificadas e, além de concentrar apatita, pode originar alumino-fosfatos do grupo da crandalita, goyazita, gorceixita, plumbogumita, florencita.

Dados geoquímicos classificam as rochas como calciocarbonatitos e aquelas hidrotermalizadas são classificadas como ferrocarbonatitos e magnesiocarbonatitos. Sugere-se uma evolução química no sentido das assembleias dominantemente calcíticas, menos diferenciadas, passando cada vez mais para dolomíticas até anqueríticas, mais diferenciadas.

\section{AGRADECIMENTOS}

Ao apoio da Companhia Baiana de Pesquisa Mineral - CBPM e a Pós-Graduação em Geociências da Universidade Estadual Paulista- UNESP

\section{REFERÊNCIAS}

ALKMIM, F. F.; BRITO NEVES, B. B. DE; ALVES, J. A. C. Arcabouço tectônico do Cráton São Francisco: uma revisão. In: SIMPÓSIO SOBRE O CRÁTON SÃO FRANCISCO, 2. 1993, Salvador. Anais... Salvador: SBG/SGM, v. 1, p. 45-62.

ALMEIDA, F. F. M. DE. O Cráton São Francisco. Revista Brasileira de Geociências, v. 7, n. 4, p. 349-367, 1977.

ANTONINI, P.; COMIN-CHIARAMONTI, P.; GOMES, C. B.; CENSI, P.; RIFFEL, B. F.; YAMAMOTO, E. The Early Proterozoic carbonatite complex of Angico dos Dias, Bahia State, Brazil: geochemical and Sr-Nd isotopic evidence for an enriched mantle origin. Mineralogical Magazine, v. 67, n. 5, p. 1039-1057, 2003.

BARKER, D. S. Field relations of carbonatites. In: Carbonatites, Genesis and Evolution. Bell, K. (ed.), Unwin Hyman Ltd, London: p. 38-63, 1989.

BOYNTON, W. V. Cosmochemistry of the rare earth elements; meteorite studies. In: Rare earth element geochemistry. Henderson, P. (ed.), Elsevier Sci. Publ. Co., Amsterdam. p. 63-114, 1984.

COMIN-CHIARAMONTI, P. \& GOMES, C. B. Mesozoic to Cenozoic Alkaline Magmatism in the Brazilian Platform. Editora da Universidade São Paulo, 750 p., 2005.

GALVANI. Mapa Geológico/Topográfico. 1: 5.000, 2013.

GITTINS, J. The origin and evolution of carbonatite magmas. In: Carbonatites, Genesis and Evolution. Bell, K. (ed.), Unwin Hyman, London, p. 580-599, 1989.

GOMES, C.; ANTONINI, P.; CASTORINA, F.; COMINCHIARAMONTI, P.; YAMAMOTO, E. A associação alcalino-carbonatítica pre-cambriana de Angico dos Dias: características geoquímicas. In: VI CONGRESSO DE GEOQUÍMICA DOS PAÍSES DE LÍNGUA PORTUGUESA e XII SEMANA DE GEOQUÍMICA. Faro, 2001. Actas... Faro/Portugal, p. 96-97.

HALL, A. Igneous Petrology. Prentice Hall, p. 417, 1996.
KAHN, H.; CASSOLA, M. S.; OBA, C. A. I.; LIBERAL, G. S. E.; RIFFEL, B. F. Caracterização tecnológica do minério residual de fosfato de Angico dos Dias, BA. In: ENCONTRO NACIONAL DE TRATAMENTO DE MINÉRIOS E HIDROMETALURGIA, 14, Salvador, 1990. Anais... Salvador. ABM: v.1, p. 196-211.

LAPIN, A. V.; RIWANUCHI, W.; PLOSHKO, V.V. Carbonatitos lineares de cinturões móveis: uma síntese. Revista Brasileira de Geociências, v. 29, p. 483-490, 1999.

Le MAITRE, R. W. Igneous Rocks: a Classification and Glossary of Terms: Recommendations of the International Union of Geological Sciences Subcommission on the Systematics of Igneous Rocks. Cambridge University Press, Cambridge, UK. 2002.

LIBERAL, G. S. \& CASSOLA, H. L. O depósito de fosfato Angico dos Dias, Ba; geologia, beneficiamento e aproveitamento econômico. In: CONGRESSO BRASILEIRO DE MINERAÇÃO 3o, São Paulo, 1989. IBM. Coletânea de Trabalhos Técnicos... IBM. v. 2. p. 266-287,

LUCIANO, R. L. Petrografia e geoquímica das rochas metacarbonatíticas do Complexo Angico dos Dias, divisa Bahia/Piauí, Brasil. Rio Claro. 2016, 273p. Tese (Doutorado). Instituto de Geociências e Ciências Exatas Universidade Estadual Paulista.

LUCIANO, R.L. \& GODOY, A.M. Geologia do Complexo Metacarbonatítico de Angico dos Dias, divisa Bahia/Piauí, Brasil. São Paulo, UNESP, Geociências, v. 36, n. 2, p. 301 314, 2017.

LUCIANO, R. L. \& GODOY, A. M. Petrografia das rochas do Complexo Metacarbonatítico de Angico dos Dias, divisa Bahia/Piauí, Brasil. São Paulo, UNESP, Geociências, v. 36, n. 4, p. 655-671, 2017.

MARIANO, A. N. Analytival report on rocks from Angico dos Dias. Bahia, CBMM, 1987. 
SANTOS, C. N. Micromorfologia, geoquímica e aspectos tecnológicos da apatita da associação alcalinometacarbonatítica pré-cambriana de Angico dos Dias, BA. São Paulo, 131p., 2001. Dissertação (Mestrado), Instituto de Geociências - Universidade de São Paulo.

SILVA, A. B,; LIBERAL, G. S.; ISSA FILHO, A.; RODRIGUES, C. S.; RIFFEL B. F. Depósito de fosfato em carbonatito pré-cambriano, Angico dos Dias-Ba. SBG, Salvador. 15p., 1987.

SILVA, A. B.; LIBERAL G. S.; GROSSI SAD, J. H.; ISSA FILHO, A.; RODRIGUES, C. S.; RIFFEL B. F. Geologia e petrologia do Complexo Angico dos Dias (Bahia, Brasil), uma associação metacarbonatíticas pré-cambriana. Geochimica Brasiliensis, v. 2, n. 1, p. 81-108, 1988.

SILVA, A. B.; LIBERAL, G. S.; RIFFEL, B. F.; ISSA FILHO, A. Depósito de fosfato de Angico dos Dias, Campo Alegre de Lourdes, Bahia. Principais Depósitos Minerais do Brasil, DNPM. v. 4, p. 123-130, 1997.

STRECKEISEN, A. L. Classification and nomenclature of volcanic rocks, lamprophyres, carbonatites, and melilitic rocks: Recommendations and suggestions of the IUGS Subcommission on the Systematics of Igneous Rocks. Chainnan, IUGS Subcommission Mineralogishes Institut, Sahlistrasse, 6. Geology, v. 7, p. 331-335, 1979.
THOMPSON, R. N. Magmatism of the British Tertiary province. Scottish Journal of Geology, v. 18, p. 49-107, 1982.

TORQUATO, J. R. F. Estudo isotópico de C e $\mathbf{O}$ em carbonatos. Angico dos Dias - Relatório Interno - CBMM. 1987.

WOOLLEY, A. R. \& KEMPE, D. R. C. Carbonatites: Nomenclature, average chemical composition and element distribution. In Carbonatites: Genesis and Evolution. Bell, K. (ed.) Unwin Hyman, London, p 1-14, 1989.

WOOLLEY, A. R. \& KJARSGAARD, B.A. Paragenetic types of carbonatite as indicated by the diversity and relative abundances of associated silicate rocks: evidence from a global database. Canadian Mineralogist, v. 46, p. 741-752, 2008.

WOOLLEY, A. R. A discussion of carbonatite evolution and nomenclature, and the generation of sodic and potassic fenites. Mineralogical Magazine, v. 46, p. 13-17, 1982.

Submetido em 20 de junho de 2016 Aceito em 17 de março de 2017 